\title{
Serviceability limit state design of deep foundations
}

\author{
F. NAGHIBI* , G. A. FENTON*† and D. V. GRIFFITHS $\$ \S$
}

\begin{abstract}
Although the settlement of deep foundations (piles) is not generally a concern if the piles are driven to refusal, settlement can become a design issue if no stiff substratum is encountered. This paper investigates the reliability-based design factors required for the serviceability limit state design of deep foundations. The goals of the paper are first to develop a probabilistic deep foundation model, which includes the effects of spatial variability and which is validated by simulation, and second to recommend the geotechnical resistance factors required to achieve specified target reliability indices against excessive settlement of deep foundations.
\end{abstract}

KEYWORDS: design; elasticity; failure; finite-element modelling; footings/foundations; limit state design/ analysis; piles; settlement; statistical analysis

\section{INTRODUCTION}

Deep foundations, or piles, are structural members made of steel, concrete and/or timber, which transmit some or all of the applied load to the ground below the surface. Piles can sometimes be costly, yet may be necessary to ensure structural safety in situations where the upper soil layer is highly compressible and/or too weak to support the applied load. The ground usually increases in strength with depth and piles are used to transfer the load to underlying bedrock or a stronger soil layer. Piles resting on a stiffer stratum are called end-bearing. If not end-bearing, they are often called floating piles, where most of the resistance is derived from skin friction and/or cohesion. To simplify the random soil model, only floating piles are considered in this paper.

To design a pile against entering the serviceability limit state - that is, against entering a failure state where the pile's actual settlement exceeds a maximum tolerable settlement a settlement prediction model is required. If the model is good, then it will provide a good estimate of the mean pile settlement and the in-situ actual pile settlement will be due to natural 'residual' soil variability around the predicted mean. The settlement prediction model is used to determine the pile design such that the predicted mean settlement is some fixed fraction (specified by the load and resistance factors) of the maximum tolerable settlement. If the settlement prediction model is poor, then it also contributes to the variability in the prediction of the actual settlement. This source of variability will be referred to here collectively as the 'degree of site and prediction model understanding', which includes $(a)$ the degree of understanding of the ground properties and geotechnical properties throughout the site, and $(b)$ the accuracy and degree of confidence about the numerical performance prediction model used to estimate the serviceability geotechnical resistances.

Manuscript received 1 March 2014; revised manuscript accepted 19 September 2014. Published online ahead of print 29 October 2014.

Discussion on this paper closes on 1 March 2015, for further details see p. ii.

* Department of Engineering Mathematics, Dalhousie University, Halifax, NS, Canada.

$\dagger$ Faculty of Civil Engineering and Geosciences, Delft University of Technology, Delft, The Netherlands.

\$Division of Engineering, Colorado School of Mines, Golden, Colorado, USA.

$\S$ Australian Research Council Centre of Excellence for Geotechnical Science and Engineering, University of Newcastle, Callaghan, NSW, Australia.
It is assumed in this paper that a sufficiently accurate settlement prediction model is used for the pile design, so that model error itself is attributable only to errors in the soil parameters used in the model - that is, to the degree of site understanding. This is probably a reasonable assumption, since if the (possibly non-linear) properties of the soil through which the pile passes, along with the nature of the interface between the pile and the soil, are all well known, then models exist which can provide very good estimates of the mean pile settlement.

This paper is not attempting to provide an improved settlement prediction model. In fact a decision about the degree of site and prediction model understanding used in the pile design process is left to the designer. This paper concentrates on the residual settlement variability (around the mean) after the design has been performed. It is assumed that this variability arises from the spatial variability of the soil itself, along with uncertainty in the soil property estimates used in the prediction model.

The main goal of this paper is to investigate the probabilistic behaviour of the settlement of a pile subjected to a random vertical load and supported by a spatially random soil, and to use this understanding to allow the determination of the resistance factors required in the design process. It is assumed here that the term 'resistance' refers to the force which must be applied to the pile in order to displace it into the soil by the maximum tolerable settlement for serviceability. This is the maximum resistance that the pile can provide at the serviceability limit state. The load and resistance factor design (LRFD) approach is then applied for the serviceability limit state (SLS) by specifying that the factored pile resistance be at least equal to the factored applied loads or actions. As discussed above, the settlement prediction model itself only changes the pile design, not its probability of failure, thus any reasonable settlement prediction model can be employed so long as it gives reasonable response results in the vicinity of the mean settlement point and reflects uncertainties in its input parameters in a reasonable fashion (e.g. if the soil parameters are incorrectly estimated to be weaker than they actually are, a longer pile than necessary will be designed). The choice in the mean settlement prediction model, so long as it gives an accurate estimate of the mean settlement given perfect information about a particular site, will have no effect on the required resistance factors. Since the stress-strain curves typical of pile settlement are usually relatively smoothly varying, a linearisation in the vicinity of the mean will be employed in 
this paper. That is, the soil will be assumed to be linearly elastic around the mean settlement point, and a linear elastic model will also be used as the settlement prediction model.

A reliability-based design approach, specifically the LRFD approach, is implemented within the random finite-element method (RFEM) to perform this investigation. LRFD is part of the limit states design (LSD) approach, which basically involves identifying possible failure modes (limit states) and ensuring that the factored resistance to that failure mode exceeds the factored load effects which are trying to cause the failure. At the SLS corresponding to excessive settlement, the LRFD design requirement can be expressed as

$$
\phi_{\mathrm{gs}} \hat{R}_{\mathrm{s}} \geqslant \sum_{i} \alpha_{i} \hat{F}_{i}
$$

where $\hat{F}_{i}$ is the $i$ th characteristic load effect, $\alpha_{i}$ is its corresponding load factor, $\hat{R}_{\mathrm{S}}$ is the characteristic (design) serviceability geotechnical resistance determined using characteristic geotechnical parameters, and $\phi_{\mathrm{gs}}$ is the serviceability geotechnical resistance factor. The characteristic serviceability geotechnical resistance, $\hat{R}_{\mathrm{s}}$, is a function of the soil's characteristic elastic modulus, the maximum allowable pile settlement and the pile geometry. The serviceability geotechnical resistance factor, $\phi_{\mathrm{gs}}$, is typically less than 1.0 and accounts for uncertainties in geotechnical parameters (Allen, 2005). The load factors, $\alpha_{i}$, are typically greater than 1.0 for ultimate limit states but usually assumed equal to 1.0 for SLSs, to account for uncertainty in loads. In this paper, the load factors are taken as $1 \cdot 0$, as is usual for SLS, and the design load is calculated as the sum of the unfactored dead and live loads. The LRFD requirement thus becomes

$$
\phi_{\mathrm{gs}} \hat{R}_{\mathrm{S}} \geqslant \hat{F}_{\mathrm{L}}+\hat{F}_{\mathrm{D}}
$$

where $\hat{F}_{\mathrm{L}}$ and $\hat{F}_{\mathrm{D}}$ are characteristic live and dead loads, respectively.

Characteristic load values can be defined as

$$
\begin{gathered}
\hat{F}_{\mathrm{L}}=\frac{\mu_{\mathrm{L}}}{k_{\mathrm{L}}} \\
\hat{F}_{\mathrm{D}}=\frac{\mu_{\mathrm{D}}}{k_{\mathrm{D}}}
\end{gathered}
$$

where $\mu_{\mathrm{L}}$ and $\mu_{\mathrm{D}}$ are the means of the live and dead loads, and $k_{\mathrm{L}}$ and $k_{\mathrm{D}}$ are live and dead load bias factors, respectively (Fenton et al., 2012). In general, the bias factors capture the difference between the characteristic design values and their means, and are usually defined as the ratio of the mean to characteristic value. The values of $k_{\mathrm{L}}$ and $k_{\mathrm{D}}$ are suggested by Bartlett et al. (2003) and Ellingwood et al. (1980) to be $k_{\mathrm{L}}=0.9$ and $k_{\mathrm{D}}=1 \cdot 05$. Assuming these to be correct, the characteristic loads are thus calculated to be $\hat{F}_{\mathrm{L}}=\mu_{\mathrm{L}} / 0.9$ and $\hat{F}_{\mathrm{D}}=\mu_{\mathrm{D}} / 1 \cdot 05$.

In order to determine the resistance factor required in equation (1) to achieve a target reliability, the target reliability must be established. The Eurocode design basis, BS EN 1990:2002 (BSI, 2002), suggests a one-year target reliability index of 2.9 for SLS which corresponds to an annual failure probability $2 \times 10^{-3}$. Phoon et al. (1995) suggest an annual target reliability index of 2.6 with corresponding failure probability $5 \times 10^{-3}$ for foundations at SLS, whereas Zhang \& Xu (2005) recommend a reliability index of 2.46 with annual failure probability $7 \times 10^{-3}$.

It probably makes more sense to consider lifetime failure probabilities, rather than annual, since the design lifetime is, or at least should be, targeted for all aspects of optimisation of the overall system (e.g. to consider the time value of periodic maintenance required by the design over the design lifetime, incorporating climate change effects into load and resistance models, including the effect of degradation of resistance with time, and so on). The difference between annual and lifetime target failure probabilities can be quite substantial. For example, if it is assumed that annual extremes in loads and resistances from year to year are independent, then an annual target reliability index of 2.9 $\left(p_{\mathrm{m}} \simeq 2 \times 10^{-3}\right)$ corresponds to a 50-year lifetime target reliability index of $1.35\left(p_{\mathrm{m}} \simeq 10^{-1}\right)$. The exact relationship between annual and lifetime failure probabilities, under the assumption of independence between annual load and resistance extremes, is given by $p_{\mathrm{m}}=1-\left(1-p_{\mathrm{ann}}\right)^{n}$, where $p_{\mathrm{ann}}$ is the annual target maximum acceptable failure probability and $n$ is the design lifetime in years.

The actual target lifetime failure probability will likely be somewhere between the value of $p_{\mathrm{m}}$ suggested above and the target annual failure probability because annual extremes in load and resistances are not likely to be truly independent. In addition, if a lifetime maximum failure probability is targeted, then the load and resistance distributions must also be targeted for that lifetime (and the same statement must be made about annual maximum failure probability).

The basic question is what lifetime failure probability is society willing to accept? Is society willing to accept that more than 1 in $10\left(p_{\mathrm{m}} \simeq 10^{-1}\right)$ piles will experience excessive settlement over the design life of a geotechnical system on average? Probably not, given the huge expense of repairing a foundation. Alternatively, is society willing to spend the money required to ensure that less than 1 in 10000 $\left(p_{\mathrm{m}} \simeq 10^{-4}\right)$ piles will experience excessive settlement? Probably not, especially considering the fact that piles are usually redundant systems. Excessive settlement of one pile is often mitigated by adjacent piles.

Thus, typical maximum lifetime failure probability of excessive settlement of a single pile lying somewhere between $p_{\mathrm{m}} \simeq 10^{-1}$ and $p_{\mathrm{m}} \simeq 10^{-4}$ is deemed to be reasonable, and this range has been considered in this paper. The resistance factors required to achieve these target probabilities will be recommended in the later section 'Required geotechnical resistance factors'.

To estimate the probability of excessive pile settlement, a linear elastic model is employed, as discussed above, which assumes that the soil surrounding the pile is perfectly bonded to the pile shaft through friction and/or adhesion. Any displacement of the pile is thus associated with an equivalent displacement of the adjacent soil. This displacement is assumed to be resisted by a force which is proportional to the soil's (residual) elastic modulus and the magnitude of the displacement. As stated by Vesic (1977), the fraction of pile settlement due to deformation of the soil is a constant (dependent on Poisson ratio and pile geometry) times $F / E_{\text {eff }}$, where $F$ is the applied load and $E_{\text {eff }}$ is the effective soil elastic modulus. The effective soil elastic modulus, $E_{\text {eff }}$, is defined here as the uniform (spatially constant) value of the elastic modulus which would produce a settlement identical to the actual pile settlement in a spatially variable soil (Fenton \& Griffiths, 2007).

The pile is assumed to be placed in a three-dimensional spatially random soil. A random load is applied vertically to the pile and the settlement of the pile is calculated using a linear elastic finite-element model (Smith \& Griffiths, 2004; Fenton \& Griffiths, 2005). The pile itself is assumed to be square, for reasons to be discussed later, with fixed crosssectional dimension $d \times d$. The pile length, $H$, is determined as follows.

(a) The random soil is sampled at some location over a depth $D$ (for example, as would occur if a cone penetration test (CPT) sounding were taken) to obtain a series of 
observations of the soil's residual elastic modulus (in the vicinity of the mean soil strain).

(b) The characteristic elastic modulus used in design, $\hat{E}$, is determined from the soil sample.

(c) The required pile length, $H$, is obtained by way of the LRFD requirement of equation (2).

The details are discussed in the following sections. Once the pile length has been determined, the 'failure' probability that the pile settlement exceeds the maximum tolerable settlement can be determined from the theory developed in this paper (as validated by simulation). Plots of failure probability can then be developed as a function of the statistics of the soil's residual random elastic modulus field (mean, variance and correlation length) and the resistance factor used in the design process. These plots can then be used to select the required resistance factor for given $p_{\mathrm{m}}$.

The remainder of this paper is organised as follows: the random soil and load models are described in the following two sections. The subsequent fourth section develops a theoretical approach to estimating the probability of excessive pile settlement, which is then validated by simulation in the next section entitled 'Validation of theory by Monte Carlo simulation'. In the section entitled 'Required geotechnical resistance factors', the resistance factors required to achieve a target reliability index against excessive settlement of deep foundations are recommended. Conclusions and suggested future work are presented in the final section.

\section{THE RANDOM SOIL MODEL}

The spatially varying elastic modulus field may be characterised by two numbers: one is the effective soil elastic modulus, $E_{\text {eff }}$, a value which yields the same settlement in a uniform elastic modulus field as the pile experiences in the actual spatially varying soil (Fenton \& Griffiths, 2007); the second is the characteristic soil elastic modulus, $\hat{E}$, which is an estimate of $E_{\text {eff }}$ obtained from a soil sample. Both numbers are defined in the fourth section, entitled 'Probability of excessive pile settlement', as geometric averages of the actual spatially varying elastic modulus field, $E$, which is assumed to be lognormally distributed with mean $\mu_{E}$, standard deviation $\sigma_{E}$ and spatial correlation length, $\theta_{\ln E}$. The lognormal distribution is commonly used to represent nonnegative soil properties and means that $\ln E$ is normally distributed with parameters $\mu_{\ln E}$ and $\sigma_{\ln E}$. The distribution parameters of $\ln E$ can be obtained from the mean and standard deviation of $E$ using the following transformations

$$
\begin{array}{r}
\mu_{\ln E}=\ln \left(\mu_{E}\right)-\frac{1}{2} \sigma_{\ln E}^{2} \\
\sigma_{\ln E}^{2}=\ln \left(1+v_{E}^{2}\right)
\end{array}
$$

where $v_{E}=\sigma_{E} / \mu_{E}$ is the coefficient of variation of the elastic modulus field.

The correlation coefficient between the log-elastic modulus at two points is defined by a spatial correlation function, $\rho_{\ln E}(\tau)$, in which $\tau$ is the distance between the two points. In this study, a simple isotropic, exponentially decaying (Markovian), correlation function will be employed, having the form

$$
\rho_{\ln E}(\tau)=\exp \left\{\frac{-2|\tau|}{\theta_{\ln E}}\right\}
$$

The assumption of isotropy (correlation length the same in all directions) is conservative, if the actual vertical correlation length is less than the horizontal correlation length (which is typical), since a larger vertical correlation length leads to less variance reduction when averaging over the pile length. The correlation function selected above acts between values of $\ln E$. This is because $\ln E$ is normally distributed, and a normally distributed random field is simply defined by its mean and covariance structure. The spatial correlation length, $\theta_{\ln E}$, appearing in equation (5) is loosely defined as the separation distance within which two values of $\ln E$ are significantly correlated. Mathematically, $\theta_{\ln E}$ is defined as the area under the correlation function, $\rho_{\ln E}(\tau)$ (Vanmarcke, 1984). In practice the correlation length $\theta_{\ln E}$ can be estimated by evaluating spatial statistics of the log-elastic modulus data directly (see for example, Fenton (1999)). The spatial correlation function, $\rho_{\ln E}(\tau)$, has a corresponding variance reduction function, $\gamma(V)$, which specifies how the variance is reduced upon local averaging of $\ln E$ over some volume $V$. It will be assumed in this work that averaging of the soil around a pile will take place within a box of dimension $V_{\mathrm{p}}=B_{\mathrm{p}} \times B_{\mathrm{p}} \times C$, so that $\gamma\left(V_{\mathrm{p}}\right)$ is defined by

$$
\gamma\left(V_{\mathrm{p}}\right)=\frac{1}{V_{\mathrm{p}}^{2}} \int_{0}^{V_{\mathrm{p}}} \int_{0}^{V_{\mathrm{p}}} \rho_{\ln E}\left(x_{\sim}-x_{2}\right) \mathrm{d} x_{\sim} \mathrm{d} x_{\sim}
$$

where $x_{1}$ and $x_{2}$ are spatial positions $(x, y, z)$ within $V_{\mathrm{p}}$. The pile is centred in the volume $V_{\mathrm{p}}$ in plan, although the depth $C$ will extend below the pile, as will be shown later. Note that $\gamma\left(V_{\mathrm{p}}\right)$ is essentially just the average correlation coefficient between all points within the volume $V_{\mathrm{p}}$.

Realisations of the random elastic modulus field are produced using the local average subdivision (LAS) method (Fenton \& Vanmarcke, 1990). Specifically, LAS produces a discrete grid of local averages, $G\left(x_{i}\right)$, of a standard Gaussian random field, having some correlation structure, in this case as given by equation (5), where $x_{i}$ is the spatial location of the centroid of the $i$ th element. These local averages are mapped to finite-element elastic modulus properties according to

$$
E\left(x_{\sim}\right)=\exp \left\{\mu_{\ln E}+\sigma_{\ln E} G\left(x_{i}\right)\right\}
$$

This research considers an individual pile placed in a spatially varying random soil. In general, the soil will vary in three dimensions, hence this study considers a threedimensional random field in which the pile is placed vertically at a certain position, and soil samples, as in CPT or standard penetration test (SPT) soundings, are taken vertically at some possibly other position, as illustrated in Fig. 1.

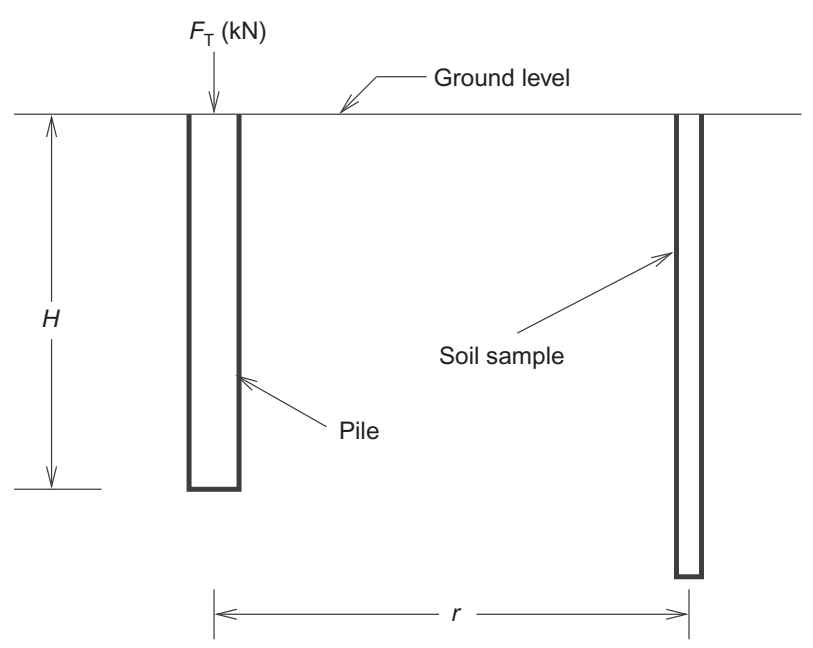

Fig. 1. Relative locations of pile and soil samples 
The samples are used to produce the pile design - in general, the further the samples are from the pile location the lower the degree of site understanding.

\section{THE RANDOM LOAD MODEL}

In this paper only live and dead loads are considered, which is a typical assumption in code development. The load employed in reliability-based design against pile settlement has two important values. One is the characteristic total load used in the pile design, which comes from current code provisions and is assumed to be deterministic: $\hat{F}=\hat{F}_{\mathrm{L}}+\hat{F}_{\mathrm{D}}=\mu_{\mathrm{L}} / 0.9+\mu_{\mathrm{D}} / 1.05$ as in equation (3). The other is the 'true', but random, total load applied to the pile, $F$. The total load is equal to the sum of the maximum lifetime live load, $F_{\mathrm{L}}$, and the relatively static dead load, $F_{\mathrm{D}}$, that is

$$
F=F_{\mathrm{L}}+F_{\mathrm{D}}
$$

where $F_{\mathrm{L}}$ and $F_{\mathrm{D}}$ are assumed here to be lognormally distributed. The mean and variance of total load, $F$, assuming live and dead loads are independent, are given by

$$
\begin{gathered}
\mu_{F}=\mu_{\mathrm{L}}+\mu_{\mathrm{D}} \\
\sigma_{F}^{2}=\sigma_{\mathrm{L}}^{2}+\sigma_{\mathrm{D}}^{2}
\end{gathered}
$$

Although the sum of two lognormally distributed random variables is not lognormally distributed, Fenton et al. (2008) found that $F$ is nevertheless approximately lognormally distributed. Assuming this to be true, the distribution parameters of the total load, $F$, are

$$
\begin{aligned}
& \mu_{\ln F}=\ln \left(\mu_{F}\right)-\frac{1}{2} \sigma_{\ln F}^{2} \\
& \sigma_{\ln F}^{2}=\ln \left(1+v_{F}^{2}\right)
\end{aligned}
$$

where $v_{F}=\sigma_{F} / \mu_{F}$ is the coefficient of variation of the total load.

In the illustrative example presented later in this paper, the characteristic load is calculated assuming that the ratio of mean dead to mean live load is $R_{\mathrm{D} / \mathrm{L}}=\mu_{\mathrm{D}} / \mu_{\mathrm{L}}=3 \cdot 0$. This choice results in a characteristic total design load, $\hat{F}$, which is approximately equal to the actual mean total load, $\mu_{F}$

$$
\begin{aligned}
\hat{F} & =\hat{F}_{\mathrm{L}}+\hat{F}_{\mathrm{D}}=\frac{\mu_{\mathrm{L}}}{k_{\mathrm{L}}}+\frac{\mu_{\mathrm{D}}}{k_{\mathrm{D}}}=\frac{\mu_{F}}{4 k_{\mathrm{L}}}+\frac{3 \mu_{F}}{4 k_{\mathrm{D}}} \\
& =\frac{\mu_{F}}{4(0 \cdot 9)}+\frac{3 \mu_{F}}{4(1 \cdot 05)}=0.99 \mu_{F} \simeq \mu_{F}
\end{aligned}
$$

\section{PROBABILITY OF EXCESSIVE PILE SETTLEMENT}

In this section, a reliability-based design methodology is presented to determine the required pile length and a subsequent theory is proposed to estimate the excessive settlement failure probability of an individual pile placed in a spatially varying soil. The theory is validated by simulation in the following section. If a mean settlement model is used which differs from the elastic model used here, as discussed in the 'Introduction', then only the design changes. As long as the 'residual' random behaviour of the in-situ pile remains approximately linearly elastic around the mean, then the results of this section will also apply to other prediction models.

To assess the probabilistic behaviour of pile settlement, the first task is to determine the nature of the settlement distribution. To accomplish this, a series of simulations, each with 2000 realisations, were performed using RFEM to estimate the pile settlement distribution. Fig. 2 shows one of the best (Fig. 2(a)) and one of the worst (Fig. 2(b)) fits of the lognormal distribution to the pile settlement histogram, having chi-square goodness-of-fit $p$-values of 0.2371 and 0.0037 , respectively. The null hypothesis for this goodnessof-fit test is that the settlement displacement follows a lognormal distribution. Fig. 2(b) rejects the null hypothesis for any significance level exceeding $0 \cdot 37 \%$. The visual inspection of the plots, however, suggests that the lognormal distribution is a reasonable distribution type for pile settlement even in the case of Fig. 2(b), as suggested also by Fenton \& Griffiths (2007)

The reliability-based design goal is to determine the required pile length, $H$, and diameter, $d$, such that the probability, $p_{\mathrm{f}}$, of exceeding a specified maximum tolerable settlement, $\delta_{\max }$, is acceptably small - that is, to find $H$ and $d$ such that

$$
\mathrm{P}\left[\delta>\delta_{\max }\right]=p_{\mathrm{f}} \leqslant p_{\mathrm{m}}
$$

in which $\delta$ is the actual (random) pile settlement, $p_{\mathrm{f}}$ is the probability of design failure, and $p_{\mathrm{m}}$ is the maximum acceptable probability of design failure. It is assumed here

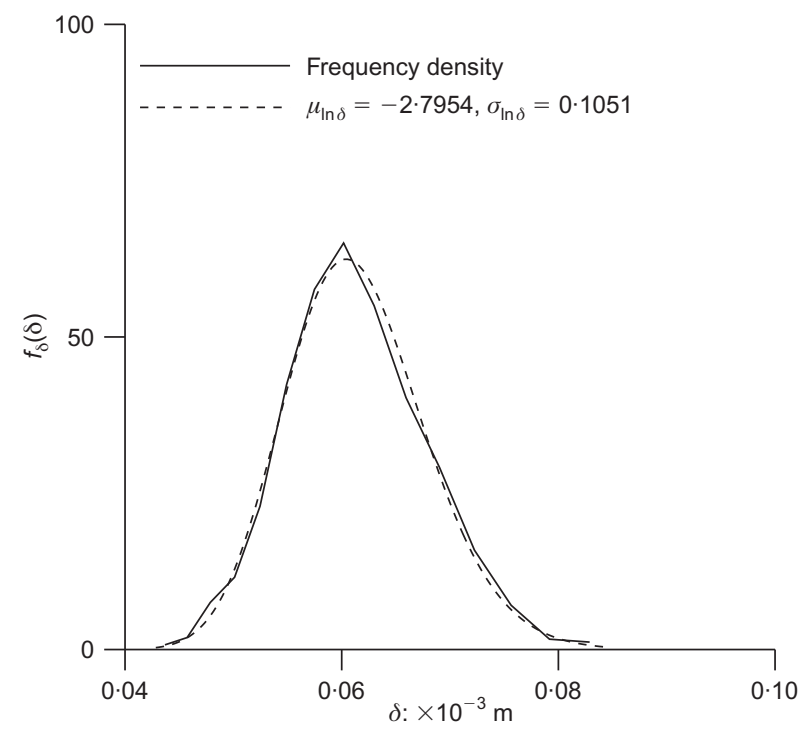

(a)

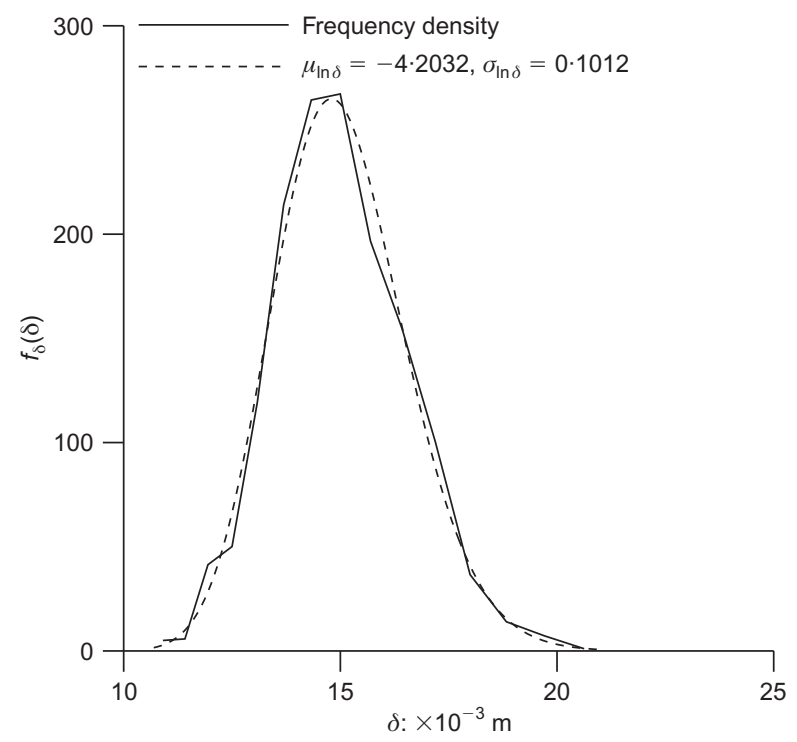

(b)

Fig. 2. Estimated and fitted lognormal distributions of settlement for: (a) $H=1 \mathrm{~m}$, and $d=0.3 \mathrm{~m} \quad(p$-value $=0.2371)$ and (b) $H=14 \mathrm{~m}$, and $d=0.3 \mathrm{~m}(p$-value $=0 \cdot 0037)$ 
that the pile type, and thus its cross-section, has already been decided on, so that its length is the only design parameter of concern. Design failure is assumed to occur if the actual pile settlement, $\delta$, exceeds the maximum tolerable settlement, $\delta_{\max }$.

Various methods are available to calculate the mean settlement of a pile, as discussed above; the basis of design used in this paper has the same form as suggested by Poulos (Poulos \& Davis, 1980) and Randolph (Randolph \& Wroth, 1978)

$$
\hat{\delta}=\frac{\hat{F}}{\hat{E} \mathrm{~d}} I_{\mathrm{p}}
$$

where $\hat{\delta}$ is the predicted pile settlement, $\hat{F}$ is the characteristic load (see equation (11)), $d$ is the pile width, $\hat{E}$ is the estimated characteristic soil elastic modulus, and $I_{\mathrm{p}}$ is a settlement influence factor, which depends on a number of parameters such as Poisson ratio, ratio of pile length, $H$, to pile width, $d$, and the pile to soil stiffness ratio, $k=E_{\mathrm{p}} / \hat{E}$, $E_{\mathrm{p}}$ being the pile elastic modulus. A function of form

$$
I_{\mathrm{p}}=a_{0}+\frac{1}{\left(H / d+a_{1}\right)^{a_{2}}}
$$

has been found here which well fits the $I_{\mathrm{p}}$ values obtained using three-dimensional finite-element analysis. The calibration of $I_{\mathrm{p}}$ is discussed in detail by Naghibi et al. (2014).

As discussed in the 'Introduction', the simple elastic prediction of $\hat{\delta}$ can be replaced by a more sophisticated nonlinear prediction. The predicted settlement, $\hat{\delta}$, given by equation (13) can be used to calculate the characteristic serviceability geotechnical resistance, $\hat{R}_{\mathrm{s}}$, introduced in equation (2). Replacing the predicted settlement, $\hat{\delta}$, with the maximum tolerable settlement, $\delta_{\max }$, and solving for corresponding value of $\hat{F}$ gives the characteristic serviceability geotechnical resistance, $\hat{R}_{\mathrm{s}}$, as

$$
\hat{R}_{\mathrm{s}}=\frac{\delta_{\max } \hat{E} \mathrm{~d}}{I_{\mathrm{p}}}
$$

If $\hat{E}$ is an estimate of the mean effective elastic modulus, then $\hat{R}_{\mathrm{S}}$ is an estimate of the mean geotechnical resistance corresponding to $\delta_{\max }$. Note that if an alternative settlement prediction model is used to determine $\hat{\delta}$, then equation (13) can be used to solve for the 'equivalent' value of $\hat{E}$ to use in equation (15).

Replacing $\hat{R}_{\mathrm{S}}$ in the LRFD design requirement of equation (2) and using $\hat{F}=\hat{F}_{\mathrm{L}}+\hat{F}_{\mathrm{D}}$ leads to

$$
\phi_{\mathrm{gs}}\left(\frac{\delta_{\mathrm{max}} \hat{E} \mathrm{~d}}{I_{\mathrm{p}}}\right) \geqslant \hat{F}
$$

The design pile length can now be determined by taking equation (16) at the equality, replacing $I_{\mathrm{p}}$ with equation (14), and solving for $H$, given an initial estimate for $d$

$$
H=d\left\{\left[\frac{1}{\left(\phi_{\mathrm{gs}} \delta_{\max } \hat{E} \mathrm{~d} / \hat{F}\right)-a_{0}}\right]^{1 / a_{2}}-a_{1}\right\}
$$

Note that equation (17) could be solved for $d$ (given $H$ ), or for $H / d$, using a root-finding algorithm, such as 1-pt iteration.

Turning attention now to the actual (random) pile settlement, $\delta$, it is hypothesised that $\delta$ can be determined using equation (13) by replacing the characteristic load $\hat{F}$ with the true (random) load $F$ and the characteristic elastic modulus $\hat{E}$ with the actual (random) effective elastic modulus $E_{\text {eff }}$

$$
\delta=\frac{F}{E_{\mathrm{eff}} d} I_{\mathrm{p}}
$$

Investigations by Fenton \& Griffiths (2002) suggest that the effective elastic modulus as seen by a shallow foundation is a geometric average of the soil's elastic modulus under the foundation. It will be similarly assumed here that the effective elastic modulus, $E_{\text {eff }}$, as seen by a pile is a geometric average of the soil's elastic modulus over a volume surrounding the pile

$$
\begin{aligned}
E_{\text {eff }} & =\exp \left\{\frac{1}{V_{\mathrm{p}}} \int_{V_{\mathrm{p}}} \ln E(\underset{\sim}{x}) \mathrm{d} \underset{\sim}{x}\right\} \\
& =\exp \left\{\frac{1}{B_{\mathrm{p}}^{2} C} \int_{0}^{B_{\mathrm{p}}} \int_{0}^{B_{\mathrm{p}}} \int_{0}^{C} \ln E(x, y, z) \mathrm{d} z \mathrm{~d} y \mathrm{~d} x\right\}
\end{aligned}
$$

where $E(x, y, z)$ is the elastic modulus of the soil at spatial position $(x, y, z)$. As mentioned above, the pile is centred on the volume $V_{\mathrm{p}}=B_{\mathrm{p}} \times B_{\mathrm{p}} \times C$.

The characteristic elastic modulus, $\hat{E}$, is estimated using observed values of the soil's elastic modulus obtained by sampling somewhere in the vicinity of the pile, which yields a sequence of $m$ observed elastic modulus values, $E_{1}^{\mathrm{o}}, E_{2}^{\mathrm{o}}, \ldots, E_{m}^{\mathrm{o}}$. If $\hat{E}$ is to be a good estimate of $E_{\text {eff }}$, then it should be similarly determined as a geometric average of the observed sample $E_{1}^{\mathrm{o}}, E_{2}^{\mathrm{o}}, \ldots, E_{m}^{\mathrm{o}}$

$$
\begin{aligned}
\hat{E} & =\left(\prod_{j=1}^{m} E_{j}^{\mathrm{o}}\right)^{1 / m}=\exp \left\{\frac{1}{m} \sum_{j=1}^{m} \ln E_{j}^{\mathrm{o}}\right\} \\
& \simeq \exp \left\{\frac{1}{V_{\mathrm{s}}} \int_{V_{\mathrm{s}}} \ln E(\underset{\sim}{x} \underset{\sim}{\mathrm{\sim}}\}\right.
\end{aligned}
$$

The probability that the design fails (see equation (12)) that is, that the actual pile settlement $\delta$ exceeds the design maximum tolerable settlement $\delta_{\max }-$ can now be estimated. Using equation (14) in equation (18), and replacing $H$ with equation (17), the actual (random) pile settlement can be expressed as

$$
\delta=\frac{\delta_{\max } \phi_{\mathrm{gs}} \hat{E}}{E_{\mathrm{eff}}}\left(\frac{F}{\hat{F}}\right)
$$

which means that the design requirement of equation (12) now becomes to find $\phi_{\mathrm{gs}}$ such that

$$
\begin{aligned}
\mathrm{P}\left[\delta>\delta_{\max }\right] & =\mathrm{P}\left[\frac{\phi_{\mathrm{gs}} \hat{E}}{E_{\mathrm{eff}}}\left(\frac{F}{\hat{F}}\right)>1\right] \\
& =\mathrm{P}\left[F\left(\frac{\hat{E}}{E_{\mathrm{eff}}}\right)>\frac{\hat{F}}{\phi_{\mathrm{gs}}}\right] \leqslant p_{\mathrm{m}}
\end{aligned}
$$

If the soil's elastic modulus, $E$, is lognormally distributed, as assumed, then both $\hat{E}$ and $E_{\text {eff }}$ will also be lognormally distributed since geometric averages preserve the lognormal distribution. In addition, if $F$ is at least approximately lognormally distributed, as assumed here (Fenton et al., 2008), the quantity $W$

$$
W=F \frac{\hat{E}}{E_{\text {eff }}}
$$

which combines all of the random quantities in equation (22), will be (at least approximately) lognormally distributed 
and its parameters can be determined by considering the individual distributions of $F, \hat{E}$ and $E_{\text {eff }}$ as follows. Since $W$ is assumed lognormally distributed, then

$$
\ln W=\ln F+\ln \hat{E}-\ln E_{\text {eff }}
$$

is normally distributed and $p_{\mathrm{f}}$ can be found from

$$
\begin{aligned}
p_{\mathrm{f}} & =\mathrm{P}\left[W>\hat{F} / \phi_{\mathrm{gs}}\right]=\mathrm{P}\left[\ln W>\ln \left(\hat{F} / \phi_{\mathrm{gs}}\right)\right] \\
& =1-\Phi\left[\frac{\ln \left(\hat{F} / \phi_{\mathrm{gs}}\right)-\mu_{\ln W}}{\sigma_{\ln W}}\right] \\
& =1-\Phi(\beta)
\end{aligned}
$$

where $\Phi$ is the standard normal cumulative distribution function, and the argument to $\Phi, \beta$, is the desired reliability index so that $p_{\mathrm{f}}=p_{\mathrm{m}}$. The required resistance factor can then be determined from equation (25) as

$$
\phi_{\mathrm{gs}}=\frac{\hat{F}}{\exp \left(\mu_{\ln W}+\beta \sigma_{\ln W}\right)}
$$

The mean and variance of $\ln W$ are

$$
\begin{aligned}
& \mu_{\ln W}=\mu_{\ln F}+\mu_{\ln \hat{E}}-\mu_{\ln E_{\text {eff }}} \\
& \sigma_{\ln W}^{2}=\sigma_{\ln F}^{2}+\sigma_{\ln \hat{E}}^{2}+\sigma_{\ln E_{\text {eff }}}^{2}-2 \operatorname{Cov}\left[\ln \hat{E}, \ln E_{\text {eff }}\right]
\end{aligned}
$$

assuming that the total load and soil elastic modulus are independent and where $\operatorname{Cov}[X, Y]$ denotes the covariance between random variables $X$ and $Y$. As discussed in the previous section entitled 'The random load model', the total load, $F$, is equal to the sum of the live load, $F_{\mathrm{L}}$, and the dead load, $F_{\mathrm{D}}$ - that is, $F=F_{\mathrm{L}}+F_{\mathrm{D}}-$ so that the mean and variance of $\ln F$ can be estimated using equations (8), (9) and (10).

With reference to equation (20), the mean and variance of $\ln \hat{E}$ are

$$
\mu_{\ln \hat{E}}=\mathrm{E}[\ln \hat{E}]=\mathrm{E}\left[\frac{1}{m} \sum_{j=1}^{m} \ln E_{j}^{\mathrm{o}}\right]=\frac{1}{m} \sum_{j=1}^{m} \mu_{\ln E}=\mu_{\ln E}
$$

where E[.] is the expectation operator, and

$$
\begin{aligned}
\sigma_{\ln \hat{E}}^{2} & =\mathrm{E}\left[\left(\ln \hat{E}-\mu_{\ln \hat{E}}\right)^{2}\right] \\
& =\mathrm{E}\left\{\left[\left(\frac{1}{m} \sum_{j=1}^{m} \ln E_{j}^{\mathrm{o}}\right)-\mu_{\ln \hat{E}}\right]^{2}\right\} \\
& \simeq \frac{\sigma_{\ln E}^{2}}{m^{2}} \sum_{i=1}^{m} \sum_{j=1}^{m} \rho\left(x_{i}^{\mathrm{o}}-{\underset{\sim}{j}}_{j}^{\mathrm{o}}\right)
\end{aligned}
$$

in which $x_{i}^{\mathrm{o}}$ is the spatial location of the centre of the $i$ th soil sample, for $i=1, \ldots, m$, and $\rho$ is the correlation function defined by equation (5). An approximation in the variance occurs owing to the fact that correlation coefficients between the local averages associated with observations are approximated by correlation coefficients between the local average centres. Assuming that $\ln \hat{E}$ represents a local average of $\ln E$ over the sample domain of volume $V_{\mathrm{s}}=$ $B_{\mathrm{s}} \times B_{\mathrm{S}} \times D$, as also suggested by equation (20), then $\sigma_{\ln \hat{E}}^{2}$ may be better estimated as

$$
\sigma_{\ln \hat{E}}^{2} \simeq \sigma_{\ln E}^{2} \gamma\left(V_{\mathrm{s}}\right)
$$

where $\gamma\left(V_{\mathrm{s}}\right)$ is the variance reduction function that measures the reduction in variance due to local averaging over the sample domain $V_{\mathrm{S}}$ (see equation (6) using $V_{\mathrm{s}}$ rather than $\left.V_{\mathrm{p}}\right)$.

Similarly, and with reference to equation (19), the mean and variance of $\ln E_{\text {eff }}$ are

$$
\begin{aligned}
\mu_{\ln E_{\text {eff }}} & =\mathrm{E}\left[\ln E_{\mathrm{eff}}\right]=\mathrm{E}\left[\frac{1}{V_{\mathrm{p}}} \int_{0}^{V_{\mathrm{p}}} \ln E(\underset{\sim}{x}) \mathrm{d} x\right] \\
& =\frac{1}{V_{\mathrm{p}}} \int_{0}^{V_{\mathrm{p}}} \mu_{\ln E} \mathrm{~d} \underset{\sim}{x}=\mu_{\ln E} \\
\sigma_{\ln E_{\mathrm{eff}}}^{2} & =\mathrm{E}\left[\left(\ln E_{\mathrm{eff}}-\mu_{\ln E_{\mathrm{eff}}}\right)^{2}\right] \\
& \simeq \frac{\sigma_{\ln E}^{2}}{V_{\mathrm{p}}^{2}} \int_{0}^{V_{\mathrm{p}}} \int_{0}^{V_{\mathrm{p}}} \rho\left({\underset{\sim}{1}}_{1}-{\underset{\sim}{2}}_{2}\right) \mathrm{d} x_{\sim} \mathrm{d} x_{\sim} \\
& =\sigma_{\ln E}^{2} \gamma\left(V_{\mathrm{p}}\right)
\end{aligned}
$$

The covariance appearing in equation (28) between the geometric average of the observed elastic modulus values over the sample volume, $V_{\mathrm{s}}$, and the effective elastic modulus as seen by the pile length over the volume $V_{\mathrm{p}}$ is obtained as follows, using the rightmost approximate in equation (20)

$$
\begin{aligned}
\operatorname{Cov}\left[\ln \hat{E}, \ln E_{\text {eff }}\right]= & \mathrm{E}\left[( \operatorname { l n } \hat { E } - \mu _ { \operatorname { l n } \hat { E } } ) \left(\ln E_{\text {eff }}-\mu_{\left.\left.\ln E_{\text {eff }}\right)\right]}\right.\right. \\
= & \mathrm{E}\left\{\left[\left(\frac{1}{V_{\mathrm{s}}} \int_{V_{\mathrm{s}}} \ln E\left({\underset{\sim}{1}}_{1}\right) \mathrm{d} x_{1}\right)-\mu_{\ln \hat{E}}\right]\right. \\
& \left.\times\left[\left(\frac{1}{V_{\mathrm{p}}} \int_{V_{\mathrm{p}}} \ln E\left({\underset{\sim}{2}}_{2}\right) \mathrm{d} x_{\sim}\right)-\mu_{\ln E_{\text {eff }}}\right]\right\} \\
\simeq & \frac{\sigma_{\ln E}^{2}}{V_{\mathrm{s}} V_{\mathrm{p}}} \int_{V_{\mathrm{s}} V_{\mathrm{p}}} \rho\left(\sqrt{r^{2}+\left(x_{\sim}-x_{2}\right)^{2}}\right) \mathrm{d} x_{\sim} \mathrm{d} x_{\sim} \\
\simeq & \sigma_{\ln E}^{2} \gamma_{V_{\mathrm{s}} V_{\mathrm{p}}}
\end{aligned}
$$

where $\gamma_{V_{\mathrm{s}} V_{\mathrm{n}}}$ is the average correlation coefficient between the log-elastic modulus samples over the sample volume, $V_{\mathrm{s}}$, and the log-elastic modulus over the pile volume, $V_{\mathrm{p}}$, and $\rho$ is the correlation function between $\ln E\left(x_{\sim}\right)$ and $\ln E\left(x_{2}\right)$ (see equation (5)). In detail, $\gamma_{V_{\mathrm{s}} V_{\mathrm{p}}}$ is defined by

$$
\begin{aligned}
\gamma_{V_{\mathrm{s}} V_{\mathrm{p}}}= & \frac{1}{V_{\mathrm{s}} V_{\mathrm{p}}} \int_{V_{\mathrm{s}}} \int_{V_{\mathrm{p}}} \rho\left(\sqrt{r^{2}+\left(x_{\sim}-{\underset{\sim}{2}}_{2}\right)^{2}}\right) \mathrm{d} x_{1} \mathrm{~d} x_{\sim} \\
= & \frac{1}{V_{\mathrm{s}} V_{\mathrm{p}}} \iint_{0}^{B_{\mathrm{s}} B_{\mathrm{s}}} \int_{0}^{B_{\mathrm{p}}} \int_{0}^{B_{\mathrm{p}}} \int_{0}^{C} \int_{0} \int_{0} \\
& \times \rho\left(\sqrt{\left(r_{x}+x_{\mathrm{s}}-x_{\mathrm{p}}\right)^{2}+\left(r_{y}+y_{\mathrm{s}}-y_{\mathrm{p}}\right)^{2}+\left(z_{\mathrm{s}}-z_{\mathrm{p}}\right)^{2}}\right) \\
& \times \mathrm{d} z_{\mathrm{p}} \mathrm{d} y_{\mathrm{p}} \mathrm{d} x_{\mathrm{p}} \mathrm{d} z_{\mathrm{s}} \mathrm{d} y_{\mathrm{s}} \mathrm{d} x_{\mathrm{s}}
\end{aligned}
$$

where $r$ is the horizontal distance between the pile centreline and the centreline of the soil sample column shown in Fig. $1, r_{x}=r+\left(B_{\mathrm{p}}-B_{\mathrm{s}}\right) / 2$, and $r_{y}=\left(B_{\mathrm{p}}-B_{\mathrm{s}}\right) / 2$. 
Substituting equations (10), (29), (31), (32), (33) and (34) into equations (27) and (28), leads to

$$
\begin{aligned}
& \mu_{\ln W}=\mu_{\ln F} \\
& \sigma_{\ln W}^{2} \simeq \sigma_{\ln F}^{2}+\sigma_{\ln E}^{2}\left[\gamma\left(V_{\mathrm{s}}\right)+\gamma\left(V_{\mathrm{p}}\right)-2 \gamma_{V_{\mathrm{s}} V_{\mathrm{p}}}\right]
\end{aligned}
$$

If the reliability index is specified, perhaps by $\beta=-\Phi^{-1}\left(p_{\mathrm{m}}\right)$, then the geotechnical resistance factor may now be determined by equation (26).

The theoretical solution developed above is valid under the assumption that a single pile is sufficient to support the applied design load without excessive settlement (according to design). In other words, the above solution only applies if a pile can be increased in length sufficiently that its settlement becomes less than $\delta_{\max }$ with probability $p_{\mathrm{m}}$. However, some load-elastic modulus combinations are such that even an infinite length pile (of diameter $d$ and elastic modulus $\left.E_{\mathrm{p}}\right)$ will have a predicted settlement exceeding $\delta_{\max }$. This will occur if the maximum value of $I_{\mathrm{p}}$, which will be called $I_{\mathrm{p}, \max }$, required to just satisfy equation (16), where

$$
I_{\mathrm{p}, \max }=\frac{\phi_{\mathrm{gs}} \delta_{\max } \hat{E} \mathrm{~d}}{\hat{F}}
$$

is less than the minimum value available from equation (14), which occurs when $H \rightarrow \infty$

$$
b_{1}=a_{0}+\frac{1}{\left(\infty / d+a_{1}\right)^{a_{2}}}=a_{0}
$$

At the other extreme, if $I_{\mathrm{p}, \max }$ is greater than that given by equation (14) when $H \rightarrow 0$

$$
b_{0}=a_{0}+a_{1}^{-a_{2}}
$$

then no pile is required to provide adequate settlement resistance.

What this means is that if $b_{1}<I_{\mathrm{p}, \max }<b_{0}$, then the failure probability given by equation (25) is valid. If $I_{\mathrm{p}, \max }>b_{0}$, then no pile is required by design, and the probability of excessive settlement is obtained from equation (25) using $H=0$.

If $I_{\mathrm{p}, \max }<b_{1}$, then a single pile is insufficient to carry the load, within an acceptable settlement, and multiple piles must be provided. If the design load, $\hat{F}$, is assumed to be shared equally between the provided piles, and the piles are assumed to act independently, then the load applied to each pile is thus $\hat{F} / n_{\mathrm{p}}$, where $n_{\mathrm{p}}$ is the number of piles required to reduce the settlement to less than $\delta_{\max }$. Owing to the assumption of independence, the probability of excessive settlement for each pile becomes

$$
p_{\mathrm{f}}=1-\Phi\left\{\frac{\ln \left[\hat{F} /\left(n_{\mathrm{p}} \phi_{\mathrm{gs}}\right)\right]-\mu_{\ln W}}{\sigma_{\ln W}}\right\}
$$

Dividing the design load by the number of piles preserves the variance of $\ln F$ (see equation (10)), therefore equation (37) can still be used to obtain the variance of $\ln W$. The mean of $\ln F$, hence the mean of $\ln W$, is reduced as follows

$$
\mu_{\ln W}=\mu_{\ln F}=\ln \left(\mu_{F} / n_{\mathrm{p}}\right)-\frac{1}{2} \sigma_{\ln F}^{2}
$$

It can be shown that the number of piles, $n_{\mathrm{p}}$, required $b y$ design to support the load $\hat{F}$ is

$$
n_{\mathrm{p}}=\operatorname{int}\left(1+\frac{b_{1}}{I_{\mathrm{p}, \max }}\right)
$$

However, since the ground is random, the value of $\hat{E}$ is random, so that $I_{p, \text { max }}$ and thus $n_{\mathrm{p}}$ are also random.
The failure probability is thus computed using the total probability theorem as

$$
p_{\mathrm{f}}=\sum_{i=0}^{\infty} \mathrm{P}\left[F \mid n_{\mathrm{p}}=i\right] \mathrm{P}\left[n_{\mathrm{p}}=i\right]
$$

where $\mathrm{P}\left[F \mid n_{\mathrm{p}}=i\right]$ is obtained by equation (41). To find $\mathrm{P}\left[n_{\mathrm{p}}=i\right]$, it is convenient to define

$$
\begin{aligned}
f_{0} & =\frac{\ln \left(b_{0} \hat{F} / \delta_{\max } \phi_{\mathrm{gs}} d\right)-\mu_{\ln \hat{E}}}{\sigma_{\ln \hat{E}}} \\
f_{i} & =\frac{\ln \left(b_{1} \hat{F} / i \delta_{\max } \phi_{\mathrm{gs}} d\right)-\mu_{\ln \hat{E}}}{\sigma_{\ln \hat{E}}}, \text { for } i=1,2,3, \ldots
\end{aligned}
$$

then

$$
\begin{aligned}
\mathrm{P}\left[n_{\mathrm{p}}=0\right] & =\mathrm{P}\left[I_{\mathrm{p}, \text { max }} \geqslant b_{0}\right]=1-\Phi\left(f_{0}\right) \\
\mathrm{P}\left[n_{\mathrm{p}}=1\right] & =\mathrm{P}\left[b_{1} \leqslant I_{\mathrm{p}, \max }<b_{0}\right]=\Phi\left(f_{0}\right)-\Phi\left(f_{1}\right) \\
\mathrm{P}\left[n_{\mathrm{p}}=i\right] & =\mathrm{P}\left[b_{1} / i \leqslant I_{\mathrm{p}, \text { max }}<b_{i} /(i-1)\right] \\
& =\Phi\left(f_{i-1}\right)-\Phi\left(f_{i}\right), \text { for } i=2,3, \ldots
\end{aligned}
$$

The mean and variance of $\ln \hat{E}$ are defined in equations (29) and (31).

Unlike equation (25), equation (44) is not easily inverted to solve for the required resistance factor, $\phi_{\mathrm{gs}}$; that is, finding $\phi_{\mathrm{gs}}$ such that equation (12) is satisfied. To obtain the required $\phi_{\mathrm{gs}}$, root-finding algorithms, such as bisection, can be utilised to determine the root of

$$
p_{\mathrm{f}}-p_{\mathrm{m}}=0
$$

The calibration of $I_{\mathrm{p}}$ is done here by performing the finite-element predictions of pile settlement over a range of $H / d$ values and solving for $I_{\mathrm{p}}$ using equation (13). For $k=E_{\mathrm{p}} / \hat{E}=700$ and $v=0 \cdot 3$, the solid curve shown in Fig. 3 results. The following function was fit (by regression) to the solid curve in Fig. 3

$$
I_{\mathrm{p}}=0 \cdot 029+\frac{1}{(H / d+2 \cdot 44)^{0.939}}
$$

which is also shown on Fig. 3, but is indistinguishable from the finite-element results. The predicted $I_{\mathrm{p}}$ value given by equation (48) is used in the next section, but a more general regression fit is developed by Naghibi et al. (2014).

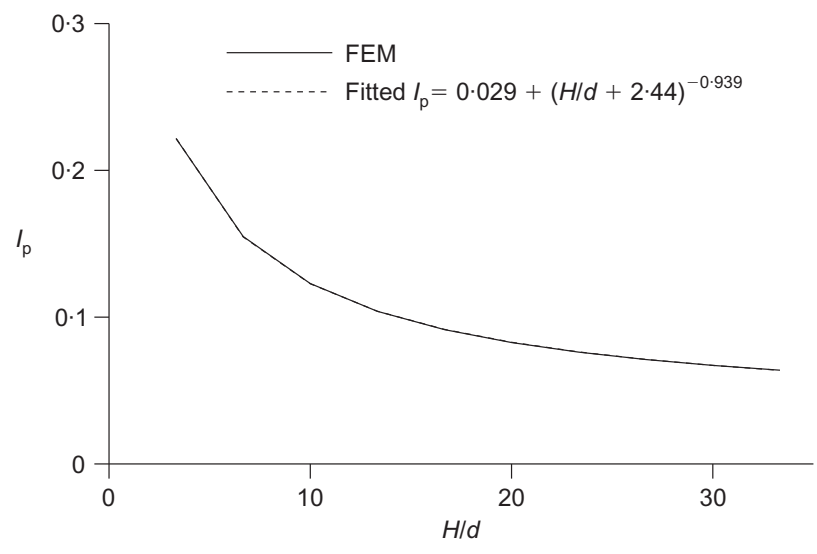

Fig. 3. Calibration of $I_{\mathrm{p}}$ using FE model for $k=700$ and $v=0 \cdot 3$ 


\section{VALIDATION OF THEORY BY MONTE CARLO SIMULATION}

The objective of this section is to validate the theory developed in the previous section by comparing to the random finite-element method (RFEM, Fenton \& Griffiths, 2008). Only one specific pile diameter is considered in the simulation, $d=0.3 \mathrm{~m}$, although several side studies were conducted to ensure that the agreement remains the same for differing pile diameters. The parameters used in the simulation are detailed in Table 1.

The simulation essentially proceeds by carrying out a series of hypothetical designs on simulated soil fields and checking to see what fraction of the designs fail (excessive settlement). In practice, the accuracy of the Monte Carlo method depends on how well the assumed probability distribution fits the real stochastic process. If the fit is reasonable, the accuracy increases with the number of simulation runs; in other words, improved results will be obtained as the number of simulation realisations increases. In detail, the steps involved in the Monte Carlo simulation are listed below.

(a) The elastic modulus, $E$, of a soil mass is simulated as a three-dimensionally spatially variable random field using the local average subdivision (LAS) method (Fenton \& Vanmarcke, 1990). The numbers of soil cells are 54 by 30 in the $X, Y$ (plan) and 30 in the $Z$ (vertical) directions and each cell size is taken to be $0.3 \mathrm{~m}$ by $0.3 \mathrm{~m}$ by $0.5 \mathrm{~m}$ in the $X$-, $Y$ - and $Z$-directions.

(b) The simulated soil is sampled along a vertical line through the soil at some distance, $r$, from the pile, see Fig. 1. The virtually sampled soil properties are used to estimate the characteristic elastic modulus, $\ln \hat{E}$, according to equation (20). A sample of depth $D=10 \mathrm{~m}$ was selected arbitrarily and, since the random field element sizes are 0.3 by $0.3 \mathrm{~m}$ in plan, the sampling volume is $V_{\mathrm{s}}=B_{\mathrm{s}} \times B_{\mathrm{s}} \times D=0.3 \times 0.3 \times 10 \mathrm{~m}^{3}$. Three sampling distances are considered: the first is at $r=0 \mathrm{~m}$, which means that the samples are taken at the pile location. In this case, uncertainty about the pile resistance only arises if the pile extends below the sampling depth or if the elastic modulus field near the piles differs significantly from the sample at the pile. Typically, probabilities of failure when $r=0 \mathrm{~m}$ are very small. The other two sample distances considered are $r=5 \mathrm{~m}$ and $r=10 \mathrm{~m}$, corresponding to reducing understanding of the soil conditions at the pile location. Note that it is really the ratio, $r / \theta_{\ln E}$, which affects the failure probability and a

Table 1. Parameters used in validation of theory

\begin{tabular}{l|l}
\hline Parameters & Values considered \\
\hline$\mu_{\mathrm{L}}$ & $400 \mathrm{kN}$ \\
$v_{\mathrm{L}}=\sigma_{\mathrm{L}} / \mu_{\mathrm{L}}$ & $0 \cdot 27$ \\
$\mu_{\mathrm{D}}$ & $1200 \mathrm{kN}$ \\
$v_{\mathrm{D}}=\sigma_{\mathrm{D}} / \mu_{\mathrm{D}}$ & $0 \cdot 1$ \\
Poisson ratio, $v$ & $0 \cdot 3$ \\
$\mu_{E}$ & $30 \mathrm{MPa}$ \\
$v_{E}$ & $0 \cdot 1,0 \cdot 2,0 \cdot 3,0 \cdot 4,0 \cdot 5$ \\
$\theta_{\ln E}$ & $0-30 \mathrm{~m}$ \\
$\phi_{\mathrm{gs}}$ & $0 \cdot 6,0 \cdot 7,0 \cdot 8,0 \cdot 9$ \\
$E_{\mathrm{p}}$ & $21 \mathrm{GPa}$ \\
$d$ & $0 \cdot 3 \mathrm{~m}$ \\
$\delta_{\max }$ & $0 \cdot 025 \mathrm{~m}$ \\
$B_{\mathrm{S}}$ & $0 \cdot 3 \mathrm{~m}$ \\
$B_{\mathrm{p}}$ & $2 \cdot 0 \mathrm{~m}$ \\
$\mathrm{D}$ & $10 \mathrm{~m}$ \\
$\mathrm{C}$ & $2 H$ \\
\hline
\end{tabular}

wide range in the correlation length, $\theta_{\ln E}$, has been considered.

(c) Once the characteristic elastic modulus has been established, the required design pile length, $H$, is calculated using equation (17) for a specified value of $\phi_{\mathrm{gs}}$ (note, $k=E_{\mathrm{p}} / \hat{E}=700$ and equation (48) were used in this step).

(d) Dead and live loads, $F_{\mathrm{D}}$ and $F_{\mathrm{L}}$, are simulated as independent lognormally distributed random variables and then added to produce the actual total load on the pile, $F=F_{\mathrm{L}}+F_{\mathrm{D}}$.

(e) The 'true' pile settlement, $\delta$, is computed using the finiteelement method, the details of which can be found in Naghibi et al. (2014). If $\delta>\delta_{\max }$ then the pile is assumed to have failed.

( $f$ ) The entire process from step $(a)$ to step $(e)$ is repeated $n_{\text {sim }}$ times (where $n_{\text {sim }}=2000$ in the present study). If $n_{\mathrm{f}}$ of these repetitions result in a pile failure, then an estimate of the probability of failure is $p_{\mathrm{f}}=n_{\mathrm{f}} / n_{\mathrm{sim}}$.

$(g)$ Repeating steps $(a)$ through $(f)$ using various values of $\phi_{\mathrm{gs}}$ in the design step allows plots of failure probability against geotechnical resistance factor to be produced for the various sampling distances, coefficients of variation of the elastic modulus and correlation lengths.

It is recognised that pile settlement becomes non-linear after about $2 \%$ of the pile diameter, and so the elastic modulus mean used in this simulation must be considered to be a secant modulus which approximates the curved nature of the actual pile load-settlement curve. However, as discussed earlier, the details of the mean settlement predictor used to design the pile are not important, and of course, the reader is encouraged to use the best settlement prediction available to them. The linear model used in this paper is, however, the best currently available to predict the effects of spatial variability of the soil on the required resistance factor.

The failure probabilities estimated by theory, by way of equation (44), can be superimposed on the simulation-based failure probability plots, allowing a direct comparison of the methods. Fig. 4 illustrates the agreement between theory and simulation for $v_{E}=0 \cdot 3$, and various resistance factors, $\phi_{\mathrm{gs}}$, when the soil is sampled at $r=0 \mathrm{~m}, r=5 \mathrm{~m}$ and $r=10 \mathrm{~m}$ from the pile location. The simulation involved only $n_{\text {sim }}=2000$ realisations and so cannot accurately resolve probabilities less than about $1 \times 10^{-3}$ - the standard deviation of the failure probability estimate is $\sqrt{p_{\mathrm{f}}\left(1-p_{\mathrm{f}}\right) / n_{\text {sim }}}$ $\simeq 0.02 \sqrt{p_{\mathrm{f}}}$ for small failure probability $p_{\mathrm{f}}$. This means that if $p_{\mathrm{f}}=1 \times 10^{-3}$, then the standard deviation of its estimate is practically the same at $0.7 \times 10^{-3}$.

The very good agreement between simulation and theory seen in Fig. 4 was obtained by adjusting by trial and error the soil volume surrounding the pile, $V_{\mathrm{p}}=B_{\mathrm{p}} \times B_{\mathrm{p}} \times C$, for use in the geometric average of equation (6). The (approximately) best averaging volume was found to occur when $B_{\mathrm{p}}=2 \mathrm{~m}$ and $\mathrm{C}=2 \mathrm{H}$, as suggested in Table 2. The remaining small discrepancies are believed to arise owing at least to the following reasons.

(a) The theory assumes that the total load is lognormally distributed, for simplicity, while the simulation assumes that the dead and live load components are perhaps more realistically individually lognormally distributed and that the total load is the sum of the two components.

(b) The simulation assumes that the soil mass is underlain by firm bedrock at a depth of $15 \mathrm{~m}$, while the theory assumes that the pile is founded in an elastic half-space. The main implications of this are that the piles in the simulation cannot exceed a length of $15 \mathrm{~m}$, and in fact 


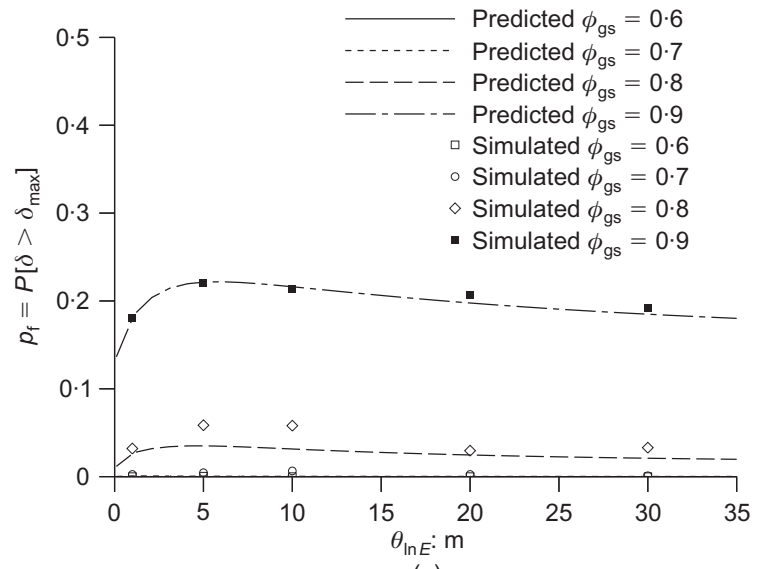

(a)

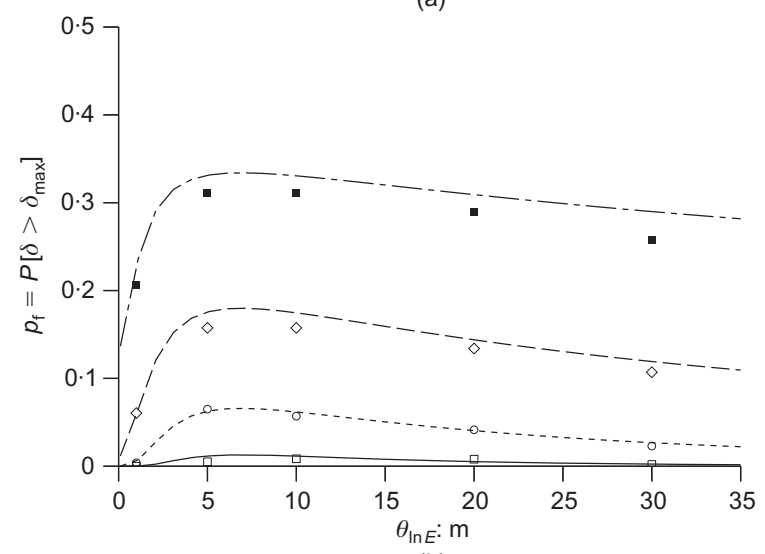

(b)

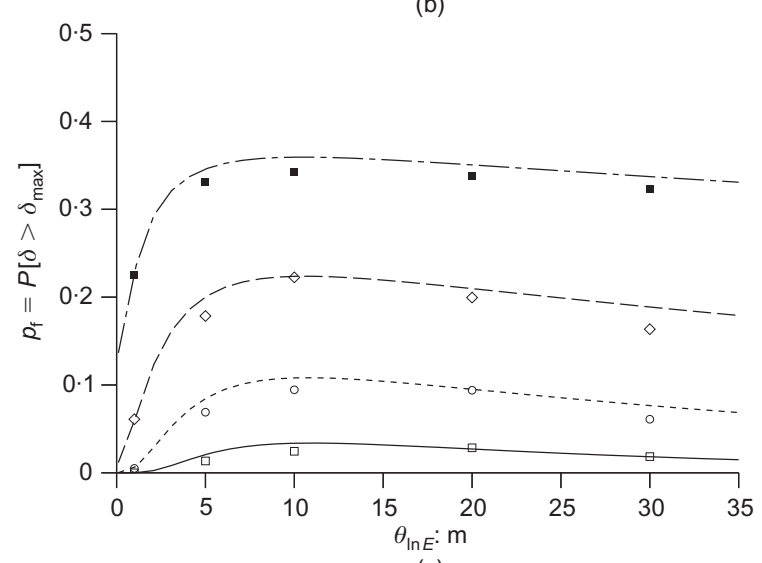

(c)

Fig. 4. Effect of correlation length, $\theta_{\ln E}$, on probability of failure, $p_{\mathrm{f}}$, for $v_{E}=0.3$, and (a) $r=0 \mathrm{~m}$; (b) $r=5 \mathrm{~m}$; (c) $r=10 \mathrm{~m}$; generated by equation (44)

boundary effects begin to show themselves well before this length. The solution was to limit the piles in the simulation to a maximum length of $H_{\max }=14 \mathrm{~m}$. If the design required a pile in excess of $H_{\max }$, then multiple piles were provided. See the previous section for a discussion of multiple piles being used. In order to compare with the simulation, the theory was adjusted temporarily by replacing equation (39) with

$$
b_{1}=a_{0}+\frac{1}{\left(H_{\max } / d+a_{1}\right)^{a_{2}}}
$$

In light of these uncertainties, the agreement between theory and simulation is deemed to be excellent so that the theory was felt to be accurate enough for the determination of resistance factors required for the design process, as discussed in the next section.

It is evident from Fig. 4 that the probability of failure
Table 2. Worst-case geotechnical resistance factors for various coefficients of variation, $v_{E}$, distance to sampling location, $r$, and acceptable failure probabilities, $p_{\mathrm{m}}$

\begin{tabular}{|c|c|c|c|c|c|}
\hline \multirow[t]{2}{*}{$r: \mathrm{m}$} & \multirow[t]{2}{*}{$v_{E}$} & \multicolumn{4}{|c|}{ Geotechnical resistance factor } \\
\hline & & $p_{\mathrm{m}}=10^{-1}$ & $p_{\mathrm{m}}=10^{-2}$ & $p_{\mathrm{m}}=10^{-3}$ & $p_{\mathrm{m}}=10^{-4}$ \\
\hline 0 & $0 \cdot 1$ & $0 \cdot 88$ & $0 \cdot 79$ & 0.73 & $0 \cdot 69$ \\
\hline 0 & $0 \cdot 2$ & $0 \cdot 86$ & $0 \cdot 77$ & $0 \cdot 72$ & $0 \cdot 68$ \\
\hline 0 & $0 \cdot 3$ & $0 \cdot 84$ & $0 \cdot 76$ & $0 \cdot 70$ & $0 \cdot 66$ \\
\hline 0 & $0 \cdot 4$ & $0 \cdot 83$ & $0 \cdot 74$ & $0 \cdot 68$ & $0 \cdot 63$ \\
\hline 0 & $0 \cdot 5$ & $0 \cdot 81$ & $0 \cdot 73$ & $0 \cdot 66$ & $0 \cdot 61$ \\
\hline 5 & $0 \cdot 1$ & $0 \cdot 86$ & $0 \cdot 76$ & $0 \cdot 69$ & $0 \cdot 64$ \\
\hline 5 & $0 \cdot 2$ & $0 \cdot 79$ & $0 \cdot 66$ & $0 \cdot 58$ & $0 \cdot 53$ \\
\hline 5 & $0 \cdot 3$ & $0 \cdot 73$ & $0 \cdot 58$ & $0 \cdot 49$ & $0 \cdot 43$ \\
\hline 5 & $0 \cdot 4$ & $0 \cdot 68$ & $0 \cdot 51$ & $0 \cdot 41$ & $0 \cdot 35$ \\
\hline 5 & $0 \cdot 5$ & $0 \cdot 63$ & $0 \cdot 45$ & $0 \cdot 34$ & $0 \cdot 28$ \\
\hline 10 & $0 \cdot 1$ & $0 \cdot 85$ & 0.75 & 0.69 & $0 \cdot 64$ \\
\hline 10 & $0 \cdot 2$ & 0.76 & 0.62 & 0.54 & $0 \cdot 48$ \\
\hline 10 & $0 \cdot 3$ & 0.69 & 0.52 & $0 \cdot 44$ & $0 \cdot 38$ \\
\hline 10 & 0.4 & 0.62 & 0.45 & $0 \cdot 36$ & $0 \cdot 31$ \\
\hline 10 & 0.5 & 0.57 & $0 \cdot 39$ & $0 \cdot 31$ & $0 \cdot 26$ \\
\hline
\end{tabular}

reaches a maximum at an intermediate correlation length of around $\theta_{\ln E} \simeq 3$ to $10 \mathrm{~m}$ for all three sampling schemes considered $(r=0,5$ and $10 \mathrm{~m})$. This is as expected, since for small and large correlation lengths the values of $\hat{E}$ and $E_{\text {eff }}$ become equal for stationary random fields and so the largest difference between $\hat{E}$ and $E_{\text {eff }}$ will occur at intermediate correlation lengths. It is also observed from Fig. 4 that the probability of failure, $p_{\mathrm{f}}$, increases with resistance factor, $\phi_{\mathrm{gs}}$, as expected. Also, $p_{\mathrm{f}}$ is smaller when the soil is sampled directly at the pile location, which is also to be expected, and means that construction savings may be achieved by improving the sampling scheme. The worst-case (lowest) resistance factor happens when the correlation length, $\theta_{\ln E}$, is approximately equal to the distance from the pile to the sampling location, a number between 1 and $10 \mathrm{~m}$ for the latter sampling schemes used in this study. This worst case is important, since the correlation length is very hard to estimate and will be unknown for most sites. In other words, in the absence of knowledge about the correlation length, the lowest resistance factor in these plots, at the worst-case correlation length, can conservatively be used. Notice in Fig. 4, that the worst-case correlation length shows some increase as the distance to the sample location increases.

Figure 5 shows the effect of the resistance factor on the probability of failure, as estimated by equation (44) for different values of $v_{E}$, and the corresponding worst-case

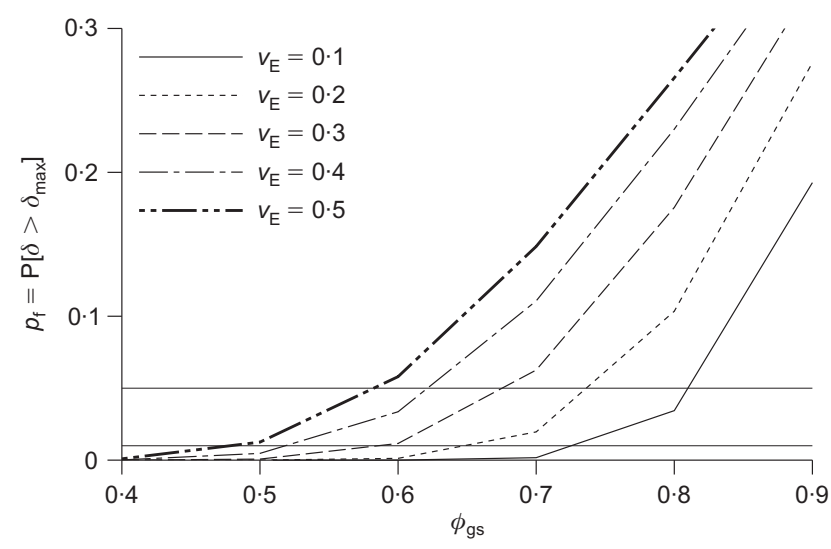

Fig. 5. Effect of resistance factor, $\phi_{\mathrm{gs}}$, on probability of failure, $p_{\mathrm{f}}$, for $r=5 \mathrm{~m}$, and $\theta_{\ln E}=5 \mathrm{~m}$, generated by equation (44) 
correlation $\theta_{\ln E}=5 \mathrm{~m}$, when the soil is sampled at $r=5 \mathrm{~m}$ from the pile location. This figure can be used for design by drawing a horizontal line across at the target probability, $p_{\mathrm{m}}$, and then reading off the required resistance factor for a given $v_{E}$. For example, if $p_{\mathrm{m}}=0.05$, it can be seen that $\phi_{\mathrm{gs}}$ is 0.58 for the 'worst case' $v_{E}=0 \cdot 5$. For the other $v_{E}$ values considered, the required resistance factor is between 0.62 and $0 \cdot 81$. For lower target probabilities, say $p_{\mathrm{m}}=0 \cdot 01$, the resistance factor for the 'worst case' $v_{E}$ decreases to 0.48 , and ranges between 0.52 and 0.72 for all other considered $v_{E}$ values. This means that construction savings may be achieved with lower target probabilities when residual soil variability is reduced by sufficient sampling.

\section{REQUIRED GEOTECHNICAL RESISTANCE FACTORS}

In this section, the values of resistance factor, $\phi_{\mathrm{gs}}$, required to achieve maximum acceptable failure probability levels $10^{-1}, 10^{-2}, 10^{-3}$ and $10^{-4}$ will be investigated. The reliability indices, $\beta$, corresponding to these four target probabilities are $1 \cdot 28,2 \cdot 3,3 \cdot 1$ and $3 \cdot 7$, respectively.

Figures 6,7 and 8 demonstrate the resistance factors required for the three sampling schemes used in this study $(r=0 \mathrm{~m}, r=5 \mathrm{~m}$, and $r=10 \mathrm{~m})$, to achieve the four maximum acceptable failure probabilities. In the case where the soil is sampled at the pile location, as depicted in Fig. 6, the resistance factor exceeds 0.80 when $p_{\mathrm{m}} \geqslant 10^{-1}$ and becomes as low as 0.61 for $p_{\mathrm{m}} \geqslant 10^{-4}$.

The smallest resistance factors in Fig. 8 correspond to the smallest acceptable failure probability, $p_{\mathrm{m}}=10^{-4}$, when the soil is sampled at $r=10 \mathrm{~m}$ away from the pile location. When the elastic modulus coefficient of variation is large

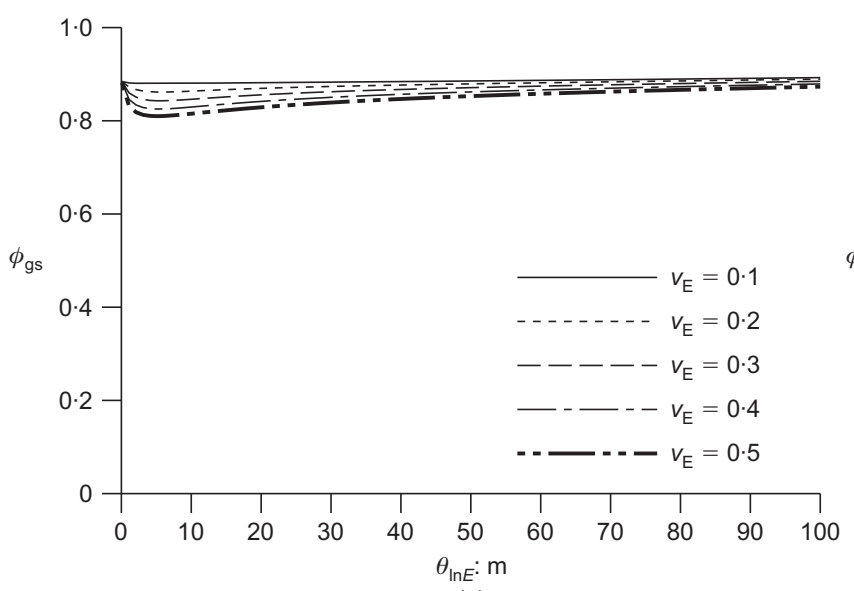

(a)

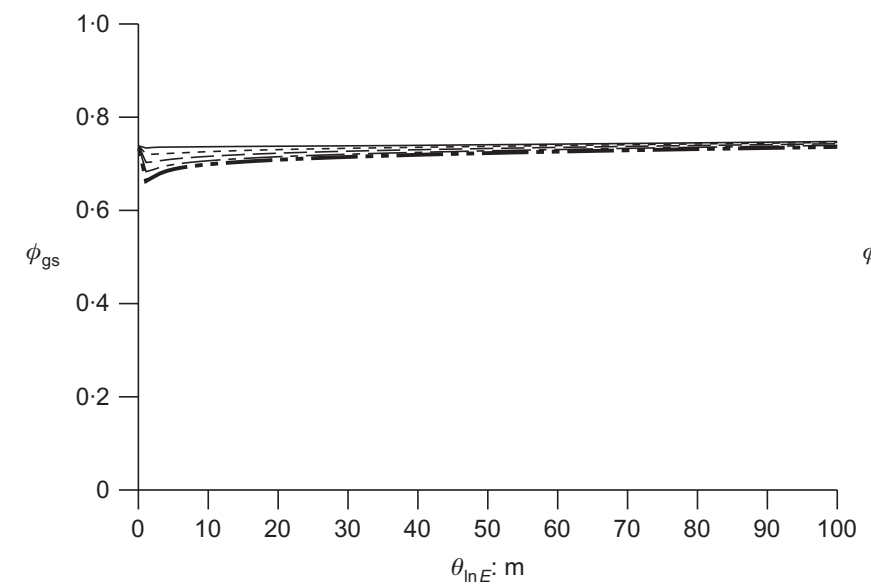

(c)
$\left(v_{E}=0 \cdot 5\right)$, the worst-case values of $\phi_{\mathrm{gs}}$ become as low as 0.26 in order to achieve $p_{\mathrm{m}}=10^{-4}$. This means that there will be a significant construction cost penalty if a highly reliable pile is to be designed using a site investigation which is insufficient to reduce the residual variability to less than $v_{E}=0 \cdot 5$. In the presence of sufficient site investigation, the upper bound in each plot (corresponding to $v_{E}=0 \cdot 1$ ) can probably be used, leading to a more economical design in terms of construction cost.

Table 2 summarises the worst-case resistance factors required to achieve the indicated maximum acceptable failure probabilities as seen in Figs 6, 7 and 8.

\section{CONCLUSIONS}

A theoretical model predicting the probability of excessive settlement of a pile was developed to allow the determination of resistance factors required to ensure that the probability of actual pile settlement exceeding the maximum tolerable settlement is acceptably small. The model assumes that the pile has been designed using a reasonable mean settlement prediction, which in this paper was a linearly elastic prediction, but which can be generalised to more sophisticated predictors. The probability of excessive settlement of the designed pile depends on the residual behaviour of the soil around its mean, which has been assumed to be predicted by a spatially varying linear elasticity field.

The theoretical model was validated by the random finiteelement method and then used to estimate geotechnical resistance factors required to achieve four maximum acceptable failure probabilities $\left(10^{-1}, 10^{-2}, 10^{-3}\right.$ and $\left.10^{-4}\right)$. The

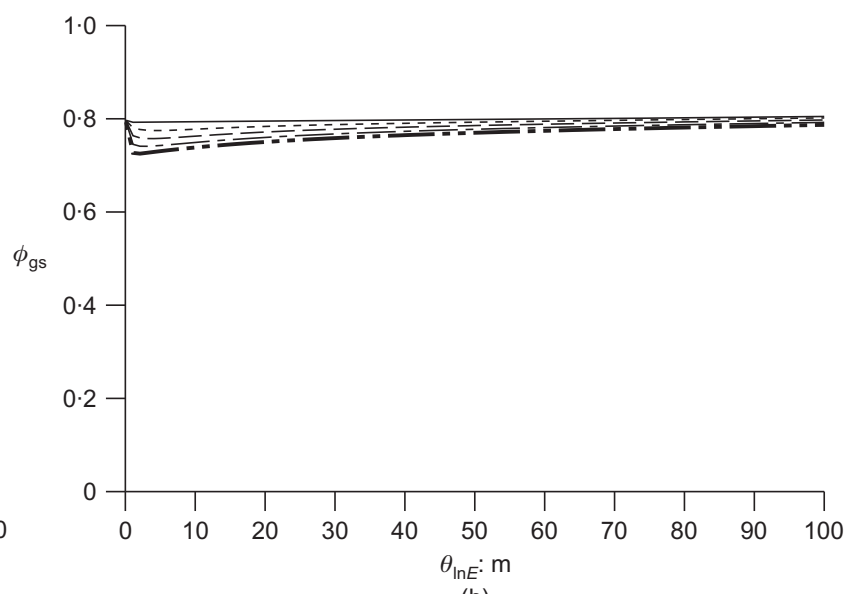

(b)

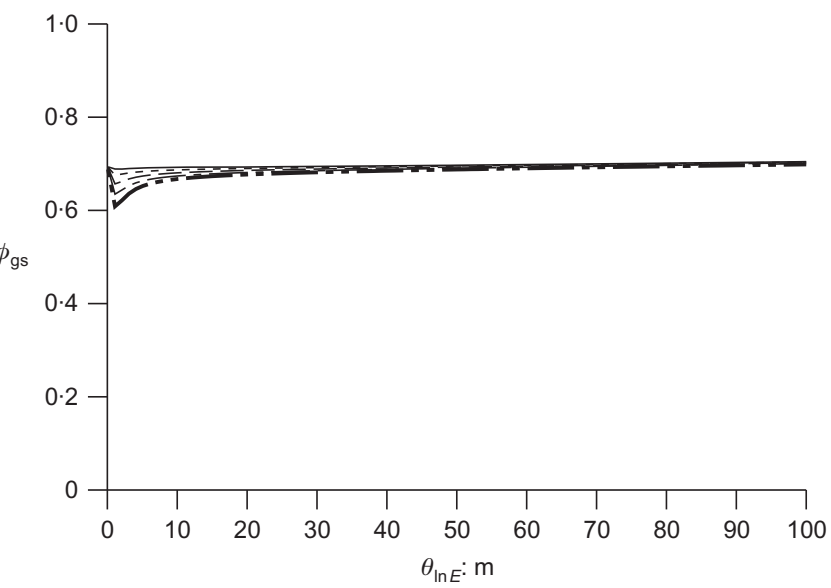

(d)

Fig. 6. Geotechnical resistance factors for soil samples taken at the pile location $(r=0 \mathrm{~m})$ : (a) $p_{\mathrm{m}}=10^{-1} ;(\mathrm{b}) p_{\mathrm{m}}=10^{-2} ;(\mathrm{c}) p_{\mathrm{m}}=10^{-3}$; (d) $p_{\mathrm{m}}=10^{-4}$ 


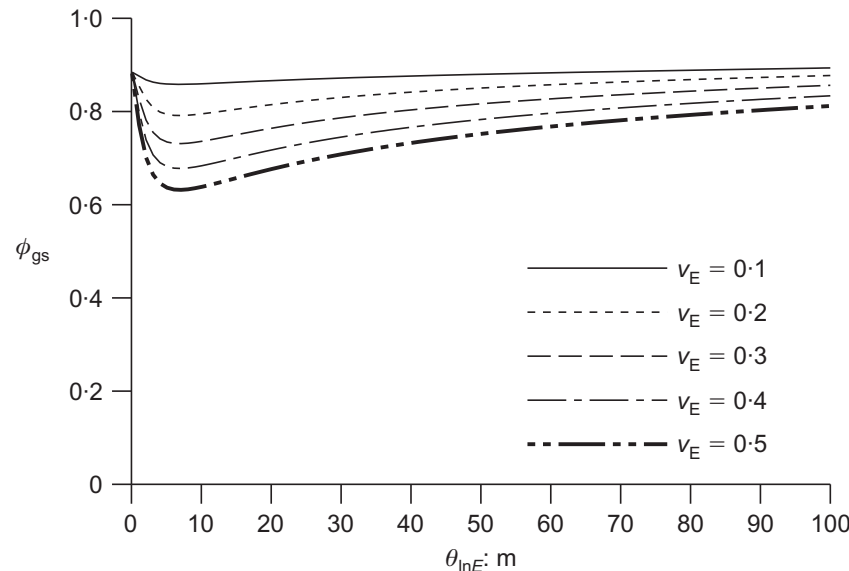

(a)

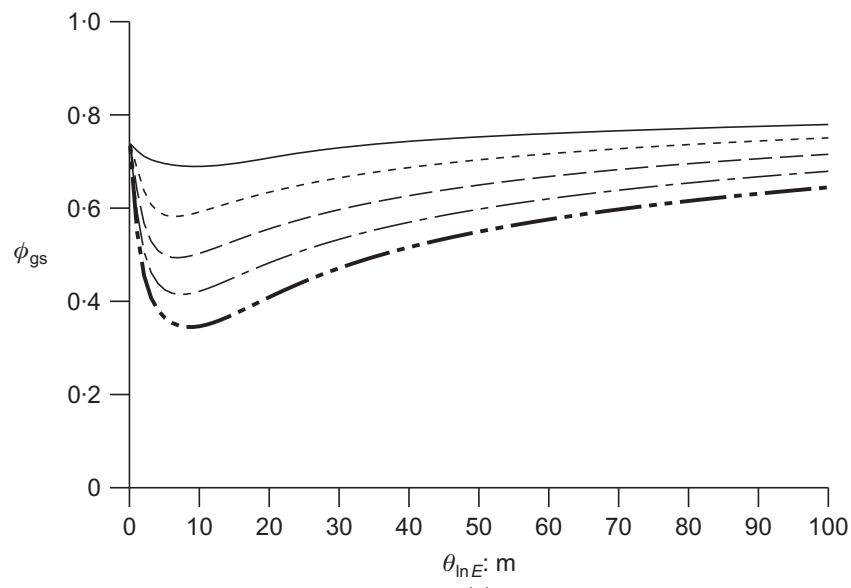

(c)

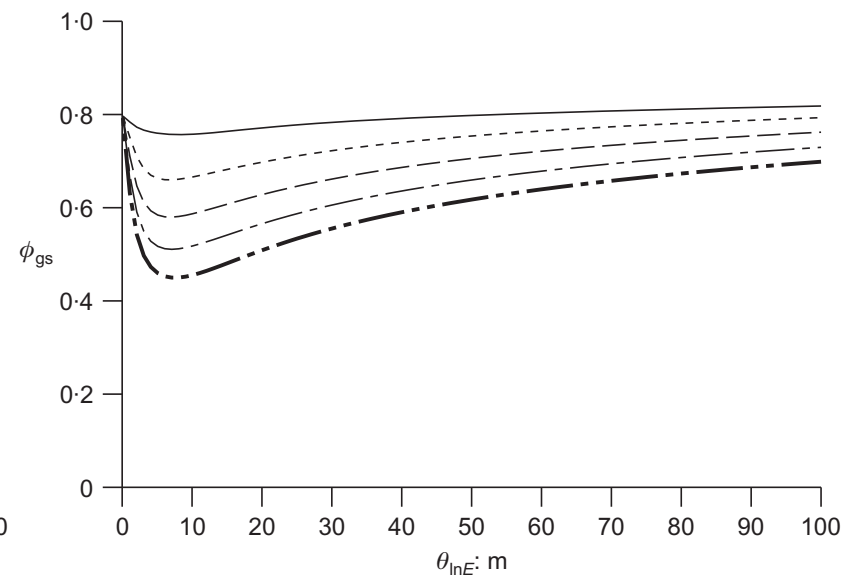

(b)

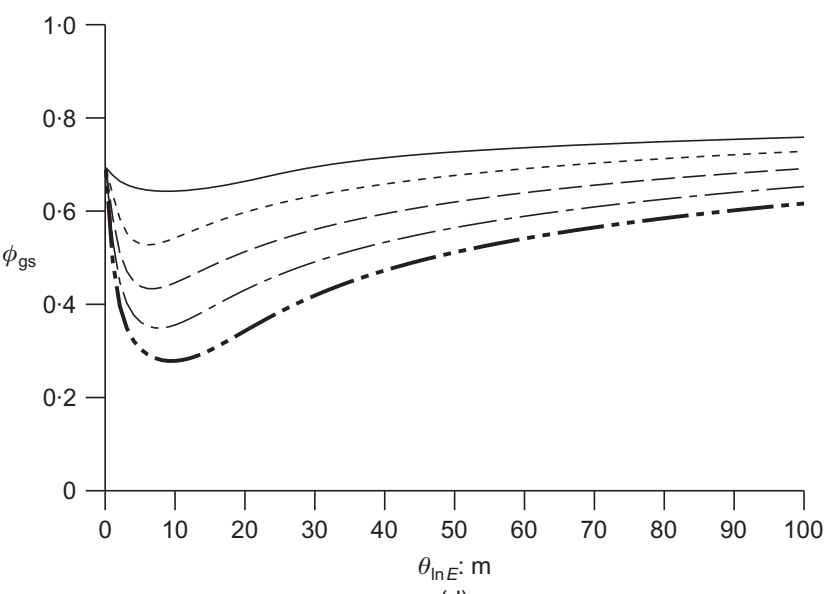

(d)

Fig. 7. Geotechnical resistance factors for soil samples taken at $r=5 \mathrm{~m}$ from the pile centreline: (a) $p_{\mathrm{m}}=10^{-1} ;$ (b) $p_{\mathrm{m}}=10^{-2}$; (c) $p_{\mathrm{m}}=10^{-3}$; (d) $p_{\mathrm{m}}=10^{-4}$

resulting resistance factors listed in Table 2 have at least two significant advantages to their use in practice

(a) the resistance factor can be calibrated to account for the level of site and model understanding, represented approximately here by the sampling distance $r$

(b) the target reliability can be explicitly adjusted for differing failure consequence and redundancy levels. For example, replacement or repair of a foundation due to excessive settlement is often extremely expensive, and can be orders of magnitude higher than the original cost of the foundation. In this case, a higher reliability (lower $p_{\mathrm{m}}$ ) may be warranted. Alternatively, if the foundation is part of a redundant system of multiple foundations (e.g. a series of piles) so that the excessive settlement of one foundation will not be noticed (the load is supported by adjacent stronger foundations), then a lower reliability (higher $p_{\mathrm{m}}$ ) may be appropriate to use for the design of the individual foundation components.

The design approach adopted in this paper takes advantage of the provision of reliability by way of a resistance factor and proceeds as follows.

(a) Decide on a pile type, so that the pile elastic modulus, $E_{\mathrm{p}}$, and diameter (or width), $d$, are known (alternatively $d$ can also be obtained in the design process - see step (e)).

(b) Decide on a maximum acceptable failure probability, $p_{\mathrm{m}}$, for the pile. As discussed above, the choice of $p_{\mathrm{m}}$ depends on the severity of failure consequences and the level of pile redundancy.

(c) Sample the soil. If a linear elastic design model is being used, estimate the characteristic soil elastic modulus using equation (20). In this paper, the estimate is a geometric average which is generally slightly lower than the arithmetic average (by $2-5 \%$ for most soils). For simplicity, an estimate of the mean elastic modulus (i.e. the arithmetic average) can also be used.

(d) Select a geotechnical resistance factor for the maximum acceptable failure probability, $p_{\mathrm{m}}$, and sampling distance from Table 2. The sampling distance has been used here as a proxy for level of site understanding. The actual geotechnical resistance factor used in design may also need to be reduced somewhat, depending on the magnitude of the model and measurement errors, as discussed below.

(e) Compute the required pile length and/or diameter, using the selected geotechnical resistance factor, $\phi_{\mathrm{gs}}$, and the maximum tolerable settlement, $\delta_{\max }$, by way of equation (17), or some other more accurate design process.

Three sampling schemes have been considered in this study. Better estimates of conditions at the pile are of course obtained when samples are taken at the pile location $(r=0 \mathrm{~m})$, which translates into lower probability of failure or, equivalently, larger geotechnical resistance factor values. The required geotechnical resistance factor also depends on the soil field uncertainty level (e.g. coefficient of variation, $v_{E}$ ), and correlation level (e.g. correlation length, $\left.\theta_{\ln E}\right)$. Since coefficient of variation, $v_{E}$ and correlation length, $\theta_{\ln E}$, are usually unknown for a given site, various $v_{E}$ values are considered in Table 2 using the worst-case correlation length (highest failure probability). Assuming a coefficient of variation of around $v_{E} \simeq 0 \cdot 3$ is 


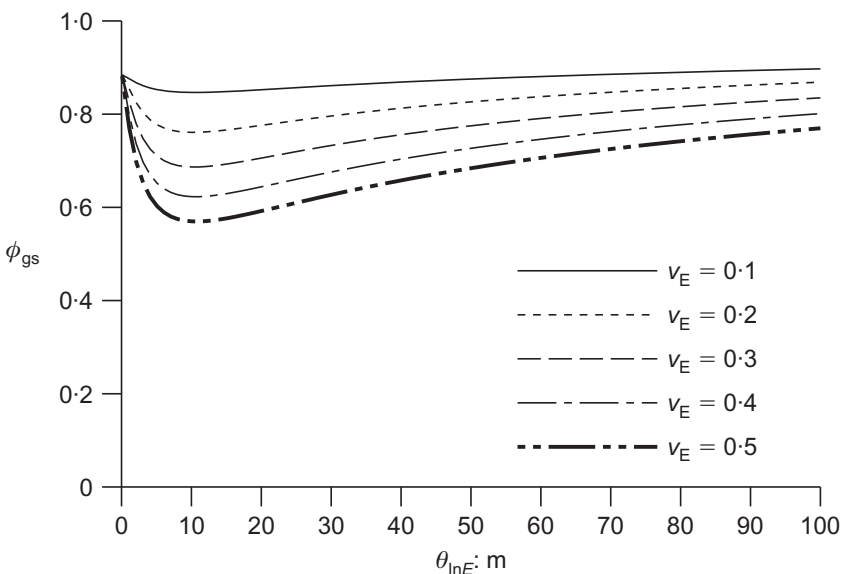

(a)

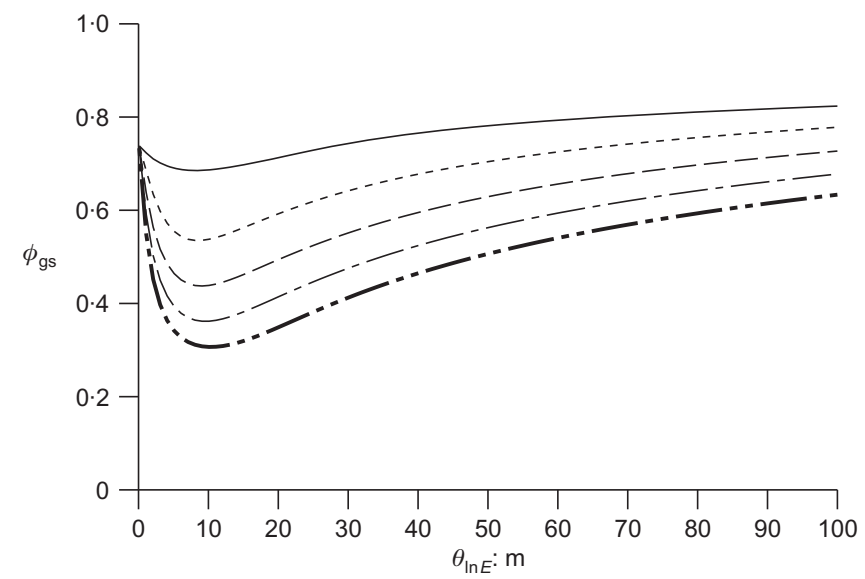

(c)

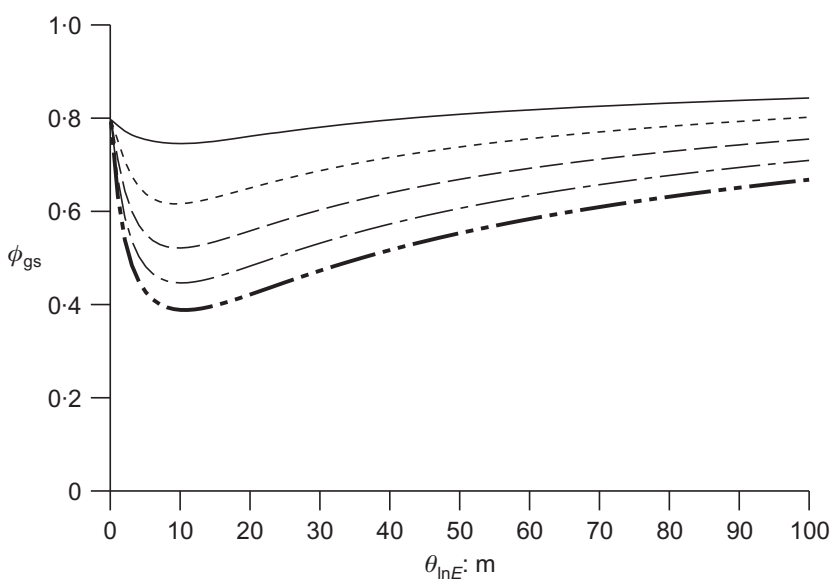

(b)

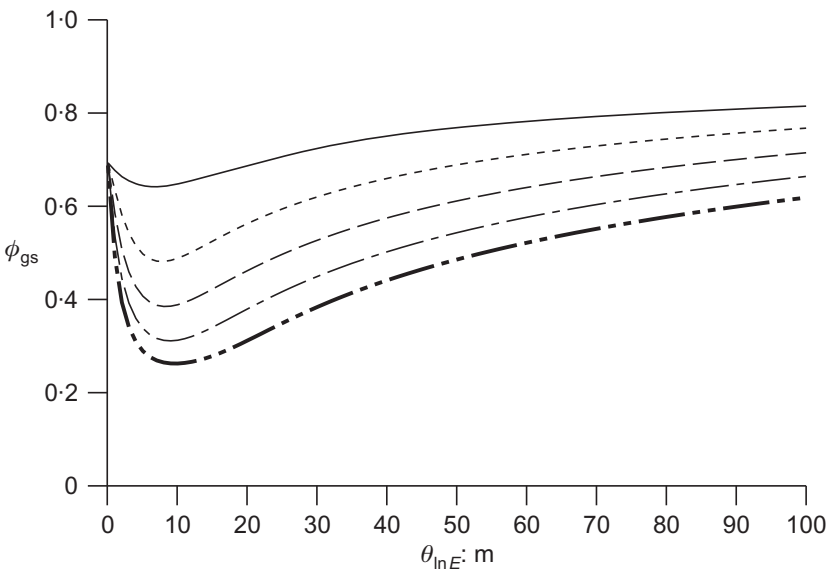

(d)

Fig. 8. Geotechnical resistance factors for soil samples taken at $r=10 \mathrm{~m}$ from the pile centreline: (a) $p_{\mathrm{m}}=10^{-1} ;$ (b) $p_{\mathrm{m}}=10^{-2}$; (c) $p_{\mathrm{m}}=10^{-3} ;$ (d) $p_{\mathrm{m}}=10^{-4}$

probably reasonably conservative. Note that the use of the worst-case correlation length can be quite conservative (see Figs 6-8).

The resistance factors recommended in this study for SLS design of deep foundations are upper bounds at the worst-case correlation length, and therefore unconservative, because measurement and model errors are not explicitly considered in their determination. These additional error sources can be accommodated here by using a value of $v_{E}$ greater than would actually be true at a site (e.g. if $v_{E}=0 \cdot 2$ at a site, the effects of measurement and model error might be accommodated by using $v_{E}=0.3$ in the relationships presented here) or by assuming that the soil samples were taken further away from the pile centreline than they actually were; for example, if low-quality soil samples are taken at the pile location $(r=0 \mathrm{~m})$ the geotechnical resistance factor corresponding to a larger value of $r$ (say $r=5 \mathrm{~m}$ ) should be used. Note, however, that the actual correlation length at the site is unlikely to be equal to the worst-case correlation length used here, so that to some extent the use of the conservative values in Table 2 may already be sufficient to account for measurement and model errors.

\section{ACKNOWLEDGEMENTS}

The authors would like to thank the Ministry of Transportation of Ontario, under a special research project grant, for its essential support of this research. In addition, the authors would like to thank Mehrangiz Naghibi for her help with the figures.

\section{NOTATION}

$a_{i} \quad$ settlement prediction parameter

$B_{\mathrm{p}}$ width of soil volume used in geometric average around pile

$B_{\mathrm{S}} \quad$ width of soil sample volume used in sample geometric average

$b_{i} \quad$ interval boundary

$C$ depth of soil volume used in geometric average around pile

$\operatorname{Cov}[X, Y]$ covariance between random variables $X$ and $Y$

$D$ depth of soil sample

$d$ pile diameter

$E$ soil's elastic modulus

$\hat{E}$ estimate of effective elastic modulus, derived from soil samples

$E_{\text {eff }}$ effective uniform soil elastic modulus that, if surrounding the pile, would yield the same settlement as actually observed

$E_{\mathrm{p}}$ pile's elastic modulus

$E_{j}^{\mathrm{o}} \quad$ one of $m$ elastic modulus soil samples actually observed

$E\left(x_{i}\right)$ elastic modulus at the spatial location $z_{i}$

E[.] expectation operator

$F$ total true (random) load

$\hat{F} \quad$ unfactored design load $=\hat{F}_{\mathrm{L}}+\hat{F}_{\mathrm{D}}$

$F_{\mathrm{D}}$ true (random) dead load

$\hat{F}_{\mathrm{D}} \quad$ characteristic dead load $=\mu_{\mathrm{D}} / k_{\mathrm{D}}$

$\hat{F}_{i} \quad i$ th characteristic load effect

$F_{\mathrm{L}}$ true (random) live load

$\hat{F}_{\mathrm{L}} \quad$ characteristic live load $=\mu_{\mathrm{L}} / k_{\mathrm{L}}$

$G\left(x_{i}\right)$ standard normal (Gaussian) random field

$H$ designed pile length

$H_{\max }$ maximum desired pile length

$I_{\mathrm{p}}$ settlement influence factor

$I_{\mathrm{p}, \max }$ maximum value of $I_{\mathrm{p}}$ required to satisfy equation (15) 
$k$ pile to soil stiffness ratio $=E_{\mathrm{p}} / \hat{E}$

$k_{\mathrm{D}}$ dead load bias factor

$k_{\mathrm{L}} \quad$ live load bias factor

$m$ number of soil observations

$n$ design lifetime (years)

$n_{\text {sim }}$ number of simulations

$p_{\text {ann }} \quad$ annual maximum acceptable failure probability

$p_{\mathrm{f}}$ probability of failure $\left(\mathrm{P}\left[\delta>\delta_{\max }\right]\right)$

$p_{\mathrm{m}} \quad$ lifetime maximum acceptable failure probability

$R_{\mathrm{S}}$ true design geotechnical resistance (random)

$\hat{R}_{\mathrm{S}} \quad$ serviceability characteristic resistance (based on characteristic soil properties)

$r$ distance between soil sample and pile centreline

$r_{x}$ plan $x$-direction distance between common corners of geometric averaging volumes at sample and pile

$r_{y}$ plan $y$-direction distance between common corners of geometric averaging volumes at sample and pile

$V_{\mathrm{p}}$ volume of geometric average around pile $\left(=B_{\mathrm{p}} \times B_{\mathrm{p}} \times C\right)$

$V_{\mathrm{S}}$ volume of sample geometric average $\left(=B_{\mathrm{s}} \times B_{\mathrm{s}} \times D\right)$

$v_{E}$ elastic modulus coefficient of variation $\left(\sigma_{E} / \mu_{E}\right)$

$v_{F}$ load coefficient of variation $\left(\sigma_{F} / \mu_{F}\right)$

$W$ true load times ratio of characteristic to equivalent elastic modulus in soils under total stress conditions $\left(F \hat{E} / E_{\text {eff }}\right)$

spatial coordinate, $(x, y, z)$ in three dimensions

$x_{i}^{\tilde{o}}$ spatial coordinate of the centre of the $i$ th soil sample

$\alpha$ total load factor

$\alpha_{i}$ load factor corresponding to the $i$ th load effect

$\beta$ reliability index

$\gamma$ variance reduction function (due to local averaging)

$\gamma\left(V_{\mathrm{p}}\right)$ variance function giving variance reduction due to averaging over soil volume surrounding pile

$\gamma\left(V_{\mathrm{s}}\right)$ variance function giving variance reduction due to averaging over sample volume

$\gamma_{V_{\mathrm{s}} V_{\mathrm{p}}}$ average correlation coefficient between elastic modulus samples over volume $V_{\mathrm{s}}$ and elastic modulus values over volume $V_{\mathrm{p}}$

$\delta$ pile settlement, positive downwards

$\hat{\delta}$ predicted pile settlement

$\delta_{\max }$ maximum acceptable pile settlement

$\theta_{\ln E}$ isotropic correlation length of random log-elastic modulus field

$\mu_{\mathrm{D}}$ mean dead load

$\mu_{E}$ mean elastic modulus

$u_{F}$ mean total load on pile

$\mu_{\mathrm{L}}$ mean live load

$\mu_{\ln E}$ mean of log-elastic modulus

$\mu_{\ln \hat{E}} \quad$ mean of logarithm of estimated effective elastic modulus (based on geometric average of elastic modulus observations)

$u_{\ln E_{\text {eff }}}$ mean of logarithm of effective elastic modulus (based on geometric average of elastic modulus over pile length $H$ )

$\mu_{\ln F} \quad$ mean total $\log$-load on pile

$\mu_{\ln W}$ mean of $\ln W$

$v$ Poisson ratio

$\rho_{\ln E}(\tau)$ common correlation function

$\sigma_{\mathrm{D}}$ dead load standard deviation

$\sigma_{E}$ standard deviation of elastic modulus

$\sigma_{\mathrm{F}}$ total load standard deviation

$\sigma_{\mathrm{L}} \quad$ live load standard deviation

$\sigma_{\ln E} \quad$ standard deviation of log-elastic modulus

$\sigma_{\ln \hat{E}}$ standard deviation of logarithm of estimated effective elastic modulus

$\sigma_{\ln E_{\text {eff }}}$ standard deviation of logarithm of effective elastic modulus

$\sigma_{\ln F} \quad$ standard deviation of log-pile load

$\sigma_{\ln W}$ standard deviation of $\ln W$

$\tau$ lag distance

$\Phi$ standard normal cumulative distribution function

$\phi_{\text {gs }}$ geotechnical resistance factor

\section{REFERENCES}

Allen, T. M. (2005). Development of geotechnical resistance factors and downdrag load factors for LRFD foundation strength limit state design, FHWANHI05052. Washington, DC, USA: U.S. Department of Transportation, Federal Highway Administration.

Bartlett, F. M., Hong, H. P. \& Zhou, W. (2003). Load factor calibration for the proposed 2005 edition of the National Building Code of Canada: Statistics of loads and load effects. Can. J. Civ. Engng 30, No. 2, 429-439, http://dx.doi.org/doi:10.1139/ L02087.

BSI (2002). BS EN 1990:2002: Eurocode - Basis of structural design. CEN (European Committee for Standardisation), Brussels, Belgium.

Ellingwood, B. R., Galambos, T. V., MacGregor, J. G. \& Cornell, C. A. (1980). Development of a probability based load criterion for American National Standard A58: Building code requirements for minimum design loads in buildings and other structures, NSC Special Publication 577. Washington, DC, USA: National Bureau of Standards, U.S. Department of Commerce.

Fenton, G. A. (1999). Estimation for stochastic soil models. ASCE J. Geotech. Geoenviron. Engng 125, No. 6, 470-485.

Fenton, G. A. \& Griffiths, D. V. (2002). Probabilistic foundation settlement on spatially random soil. ASCE J. Geotech. Geoenviron. Engng 128, No. 5, 381-390.

Fenton, G. A. \& Griffiths, D. V. (2005). Three-dimensional probabilistic foundation settlement. ASCE J. Geotech. Geoenviron. Engng 131, No. 2, 232-239.

Fenton, G. A. \& Griffiths, D. V. (2007). Reliability based deep foundation design. In Probabilistic applications in geotechnical engineering, Proceedings of the GeoDenver 2007 symposium, Denver, Colorado (eds K. K. Phoon, G. A. Fenton, E. F. Glynn et al.), GSP No. 170, pp. 1-12. Reston, VA, USA: American Society of Civil Engineers.

Fenton, G. A. \& Griffiths, D. V. (2008). Risk assessment in geotechnical engineering. New York, NY, USA: Wiley.

Fenton, G. A. \& Vanmarcke, E. H. (1990). Simulation of random fields via local average subdivision. ASCE J. Engng Mech. 116, No. 8, 1733-1749.

Fenton, G. A., Griffiths, D. V. \& Zhang, X. Y. (2008). Load and resistance factor design of shallow foundations against bearing failure. Can. Geotech. J. 45, No. 11, 1556-1571.

Fenton, G. A., Naghibi, F. \& Bathurst, R. J. (2012). Comparison of geotechnical LRFD implementations. Proceedings of the 65th Canadian geotechnical conference - GeoManitoba 2012 (editor K. Bannister), paper no. 163 (on CD-ROM). Winnipeg, Manitoba, Canada: Canadian Geotechnical Society.

Naghibi, F., Fenton, G. A. \& Griffiths, D. V. (2014). Prediction of pile settlement in an elastic soil. Comput. Geotech. 60, No. 2, $29-32$.

Phoon, K. K., Kulhawy, F. H. \& Grigoriu, M. D. (1995). Reliability-based design of foundations for transmission line structures, Report TR105000. Palo Alto, CA, USA: Electric Power Research Institute.

Poulos, H. G. \& Davis, E. H. (1980). Pile foundation analysis and design. New York, NY, USA: Wiley.

Randolph, M. F. \& Wroth, C. P. (1978). Analysis of deformation of vertically loaded piles. ASCE J. Geotech. Geoenviron. Engng 104, No. GT12, 1465-1488.

Smith, I. M. \& Griffiths, D. V. (2004). Programming the finite element method, 4th edn. New York, NY, USA: Wiley.

Vanmarcke, E. H. (1984). Random fields: Analysis and synthesis. Cambridge, MA, USA: MIT Press.

Vesic, A. S. (1977). Design of pile foundations, National Cooperative Highway Research Program Synthesis of Practice No. 42. Washington, DC, USA: Transportation Research Board.

Zhang, L. M. \& Xu, Y. (2005). Settlement of building foundations based on field pile load based on pile load tests. Proceedings of the 16th international conference on soil mechanics and geotechnical engineering, Osaka (on CD-ROM). Amsterdam, the Netherlands: IOS Press. 